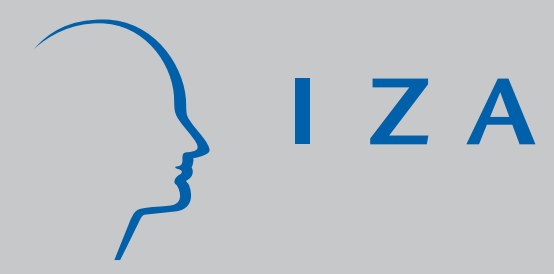

IZA DP No. 3891

Unintended Consequences of Welfare Reform: The Case of Divorced Parents

Marco Francesconi

Helmut Rainer

Wilbert van der Klaauw

December 2008 


\title{
Unintended Consequences of Welfare Reform: The Case of Divorced Parents
}

\author{
Marco Francesconi \\ University of Essex, \\ Institute for Fiscal Studies and IZA
}

Helmut Rainer

University of St. Andrews

\author{
Wilbert van der Klaauw \\ Federal Reserve Bank of New York
}

Discussion Paper No. 3891

December 2008

\author{
IZA \\ P.O. Box 7240 \\ 53072 Bonn \\ Germany \\ Phone: +49-228-3894-0 \\ Fax: +49-228-3894-180 \\ E-mail: iza@iza.org
}

\begin{abstract}
Any opinions expressed here are those of the author(s) and not those of IZA. Research published in this series may include views on policy, but the institute itself takes no institutional policy positions.

The Institute for the Study of Labor (IZA) in Bonn is a local and virtual international research center and a place of communication between science, politics and business. IZA is an independent nonprofit organization supported by Deutsche Post World Net. The center is associated with the University of Bonn and offers a stimulating research environment through its international network, workshops and conferences, data service, project support, research visits and doctoral program. IZA engages in (i) original and internationally competitive research in all fields of labor economics, (ii) development of policy concepts, and (iii) dissemination of research results and concepts to the interested public.
\end{abstract}

IZA Discussion Papers often represent preliminary work and are circulated to encourage discussion. Citation of such a paper should account for its provisional character. A revised version may be available directly from the author. 
IZA Discussion Paper No. 3891

December 2008

\section{ABSTRACT \\ Unintended Consequences of Welfare Reform: The Case of Divorced Parents ${ }^{*}$}

This paper formulates a model to examine the effects of changes in tax-benefit policy on the behavior of divorced parents and the well-being of children in single-parent households. Noncustodial parents choose the level of a child support payment to transfer to custodians. These, in turn, decide over child good expenditures and the allocation of time between market work and parenting. In general, ex-spouses fail to achieve an efficient allocation of their resources. On the custodial side, there are inefficiently high levels of labor supply and inefficiently low levels of expenditures on child goods, while on the noncustodial side child support payments are suboptimally low. Our results rationalize the adverse effects that welfare reforms might have on divorced parents and their children. Such adverse effects may arise because an increase in the custodian's effective wage, either through lower marginal income tax rates or higher childcare subsidies, reinforces the inefficiencies of divorced parents' decisions: that is, such an increase further depresses child support transfers from noncustodial parents and induces custodial parents to work even more. We explore several extensions of this model, link our findings to the existing empirical literature on the impacts of welfare reform, and discuss the implications of our results for policy and further economic analysis.

JEL Classification: D13, H31, J22

Keywords: non-intact families, in-work benefit reform, child care, child support, non-cooperation

Corresponding author:

Marco Francesconi

Department of Economics

University of Essex

Colchester CO4 3SQ

United Kingdom

E-mail: mfranc@essex.ac.uk

* The paper benefited from comments from seminar participants at Stirling, Bergen, Linz and St Andrews. The views and opinions offered in this article do not necessarily reflect those of the Federal Reserve Bank of New York or the Federal Reserve System as a whole. 


\section{Introduction}

When it comes to improving the economic circumstances of low income parents, policy makers increasingly turn to the tax and benefit system for serendipitous solutions. For example, one of the key objectives of the "making work pay" agenda in the United States, Canada, and Britain has been to boost in-work benefits offered to low-income parents (especially single mothers) through more generous amounts of tax credits, lower withdrawal (phase-out) rates, and substantial childcare subsidies. Examples include the policies implemented through the American Earned Income Tax Credit, the Canadian Self-Sufficiency Program, and the British Working Families' Tax Credit and Working Tax Credit (Michalopoulos et al. 2002; Eissa and Hoynes 2004; Morris et al. 2005; Grogger and Karoly 2005; Gennetian et al. 2005; Meyer 2007; Brewer 2008; Gregg 2008; Brewer et al. 2009).

Despite the popularity of these reforms among policy makers, however, the ways in which they may affect the overall welfare of low-income families is often not fully understood. In particular, little is known about the potential of tax-benefit-program induced behavioral responses to have an adverse impact on child well-being in lone parent families. A growing body of empirical research documents that changes in tax and benefit policies can have or have had unfavorable effects on single mothers' health and well-being (e.g., Bitler et al. 2002 and 2005; Francesconi and van der Klaauw 2007; Baker et al. 2008; Grogger and Karoly 2009; Brewer et al. 2009) as well as on a wide array of their children's outcomes (e.g., Clark-Kauffman et al. 2003; Gennetian et al. 2002 and 2005; Baker et al. 2008; Herbst and Tekin 2008; Grogger and Karoly 2009; Gregg et al. 2009). There is still insufficient appreciation for the ramifications of such unintended or unanticipated consequences of welfare reform. The contribution of this paper, therefore, is to provide a new theoretical setup that can coherently explain these undesirable effects and can also deliver testable implications on the strategic interactions between divorced parents and on child welfare.

Our study is based on the seminal contributions by Weiss and Willis $(1985,1993)$ and Del Boca and Flinn (1995). These studies, which treat labor supply decisions and post-divorce incomes of former spouses as exogenous, provide a formal analysis of the noncooperative behavior of divorced parents in terms of child support transfers and expenditures on children. ${ }^{1}$ We build on these earlier studies by (i) modeling the labor supply decision of the custodial parent and (ii) explicitly incorporating the tax-benefit program.

\footnotetext{
${ }^{1}$ Flinn (2000) allows the type of interaction between former partners, whether it is noncooperative or cooperative, to be determined endogenously. We shall return to this idea in Section 2 and in one of our extensions in Section 5 .
} 
We then focus on the effects of tax-benefit policy changes on divorced parents' labor supply, consumption and child support transfer decisions and on child well-being in single parent households. We posit that child well-being is determined by the combination of purchased goods and parental time, which in the case of single parent households reduces to the time allocated by the custodial (lone) parent only. For simplicity, the time devoted to the child by the noncustodial parent is assumed to have no effect on child well-being. In this environment, then, divorced parents make three decisions noncooperatively. The noncustodial parent chooses the amount of child support payment to transfer to the custodial parent, and the custodial parent decides over both child good expenditures and the allocation of time between market work and childcare. Each parent has preferences defined over own consumption and child welfare. Child welfare depends positively on expenditures and the amount of time the child spends with the custodial parent. One hour spent away from the custodial parent (for instance, in formal daycare, while the mother works) is assumed to contribute less (is less productive) to child welfare than one hour spent with the mother. Child welfare therefore is a local public good from the point of view of both parents, although only the custodial parent gets to decide how much to spend on child goods and how to allocate time between paid work and parenting.

With this setup, we first characterize the noncooperative behavior of divorced parents in terms of child support payments, time allocated to parenting, and child good expenditures. Because the noncustodial parent does not have control over the expenditure and time allocation decisions of the custodial parent, it is not feasible for the ex-spouses to reach a Pareto efficient allocation of their resources. As a consequence, the noncustodian provides less than optimal child support transfers. The custodian, instead, not only spends too little on child goods, but also devotes too much time to market work and too little to childcare. Thus, the inefficiencies that arise in our framework are threefold and correspond to the three parental decisions under analysis: on the custodial side, child quality suffers because of inefficiently high levels of labor supply and inefficiently low expenditures on child goods, and on the noncustodial side child support payments are suboptimally low.

Using this framework, we then investigate the impact of policy reforms that are meant to improve lone parents' well-being. We document that more generous government transfers provided to custodial parents (in the form of, say, income support or child tax credits) increase well-being of both custodial and noncustodial parents as well as that of their children. This is a straightforward result. A new result, instead, emerges when we look at the effect of increasing the custodian's effective wage, through either greater childcare subsidies or lower withdrawal (phase-out) rates or both. While standard theory suggests that an exogenous 
increase in the effective wage rate should raise lone mothers' well-being (although not necessarily that of their children), in our model it can reduce the utility of divorced custodial parents and depress the welfare of their children. This is because an increase in the mother's effective wage reinforces the inefficiencies induced by noncooperation. That is, such an increase further depresses child support transfers from noncustodial fathers and accentuates over-work among custodial mothers. This greater labor supply is the net effect of a direct substitution effect (i.e., the opportunity cost of not engaging in paid work goes up) and a strategic multiplier effect (i.e., a response to the reduced child support transfer from the noncustodian). There are circumstances (that we shall characterize later) in which these effects interact so as to offset the positive income effect to depress divorced parents' utility and child welfare.

This finding provides an important insight that has been overlooked so far: welfare policies that subsidize childcare expenditures or reduce withdrawal rates, which are most certainly intended to improve the conditions of working single parents and their children, could actually have the reverse effect. This implication is robust to the inclusion of issues of compliance with child support awards imposed by external institutional agents (e.g., courts or judges), and it is also robust to the alternative assumption that divorced parents can choose to behave cooperatively instead of noncooperatively in the case of low-income households. ${ }^{2}$

The remainder of the paper is as follows. The next section discusses the links of our contribution to the relevant literature. Section 3 sets up the basic model, while Section 4 provides the main equilibrium analysis and illustrates the effects of tax-benefit changes on divorced parents' and children's well-being. Section 5 explores two extensions of the basic model in detail, i.e., compliance with child support orders by the noncustodial parent and cooperation among divorced parents. Section 6 relates our theoretical results to some of the existing empirical evidence and discusses some ideas for future research. For ease of exposition all proofs are relegated to the Appendix.

\section{Related Literature}

Our work is closely related to a number of other previous studies on the behavior of divorced parents. Weiss and Willis (1985) address the question of why many divorced fathers allow their children's welfare to suffer as a consequence of divorce. Children are treated as collective consumption goods from the point of view of both parents. Within marriage parents' cooperative behavior allows them to overcome the inefficiencies typically associated with public goods provi-

\footnotetext{
${ }^{2}$ In an environment in which the mode of interaction between divorced parents is determined endogenously (as in Flinn [2000]), we show in Section 5 that a tax-benefit reform that increases the effective wage of custodial parents may induce low-income divorced parents to behave noncooperatively instead of cooperatively.
} 
sion. ${ }^{3}$ Upon divorce, however, the noncustodial parent cannot control the expenditure decisions of the custodial parent. This, in turn, prevents the ex-spouses from reaching an efficient allocation of their resources, with the noncustodial parent making inadequate child support payments and the custodial parent devoting too few material resources to child goods. ${ }^{4}$ Our addition to this line of thinking is that inefficient allocations may not only involve child good expenditures but also parental time devoted to childcare (as opposed to paid work). This additional dimension is very important in the context of in-work benefit reforms, because inefficiencies related to time allocation decisions might be exacerbated by such reforms.

Del Boca and Flinn (1995) develop a noncooperative framework in which both child support compliance decisions of noncustodial fathers and court-mandated child support awards can be rationalized. Structural estimates of their model, which qualitatively replicate the observed distribution of child support payments, can be used to infer the implicit weights assigned by courts to the post-divorce welfare of both parents and children. The results indicate that the weight attached to the combined welfare of custodial mothers and their children is smaller than the weight attached to the welfare of noncustodial fathers. Courts may therefore set relatively low child support orders not only because they are concerned with fathers' noncompliance but also because they assign a large weight on fathers' welfare. As illustrated in Section 5, extending our basic framework to a model that incorporates child support orders does not alter our main results.

Our results partially continue to hold when we extend our model and allow for cooperation among divorced parents to arise endogenously. In particular, a tax-benefit change that increases the effective wage of the custodial parent may induce low-income divorced parents, who would have otherwise chosen to behave cooperatively, to switch their mode of behavior and implement a noncooperative equilibrium. Conversely, high-income divorced parents may respond to such a tax-benefit change by behaving cooperatively instead of noncooperatively. This extension follows the approach proposed by Flinn (2000), in which compliance with child support orders is equivalent to parental cooperation (and efficient levels of child good expenditures can then be achieved), while noncompliance is equivalent to noncooperative behavior (and only suboptimal

\footnotetext{
${ }^{3} \mathrm{~A}$ recent strand of analysis argues that inefficient intrahousehold allocations are plausible even in marriage as long as current decisions affect future bargaining power and spouses cannot make binding commitments over allocations within marriage. See, among others, Lundberg and Pollak (2003) and our brief discussion below.

${ }^{4}$ Using data from the National Longitudinal Study of the High School of 1972, Weiss and Willis (1993) analyze the effects of spouses' incomes on transfers among divorced couples. They find that divorce transfers tend to increase with the noncustodial parent's income and to decline with the custodial parent's income, while child expenditures in the divorce state are estimated to be half of those that would occur during marriage. This last finding is consistent with the estimates reported in Jarvis and Jenkins (1999) for Britain and Page and Stevens (2004) for the United States.
} 
allocations can be attained). The type of parental interaction in the divorce state, whether cooperative or noncooperative, is determined endogenously, with compliance being observed when the gains from cooperation exceed the value of noncooperation for both parents. Structural estimates of Flinn's model indicate that an increase in child support enforcement activities (by courts or other institutional agents) have only modest positive effects on the welfare of children of divorced parents. ${ }^{5}$

Although our paper focuses on the interactions between divorced parents, the approach of the paper also has much in common with bargaining models of household decisions among married couples used in recent contributions, such as Grogger and Karoly (2009) and Francesconi et al. (2009). Both these studies point out that work-conditioned transfer programs can cause the likelihood of divorce either to rise or to fall. This is because such programs may alter the non-marital options faced by single mothers and, at the same time, they may also affect the marital utility-possibility frontier. Likewise, changes in one spouse's nonmarital alternatives induced by in-work benefit reform could affect child well-being through their influence on intrahousehold resource allocations, and this relationship again is likely to be ambiguous. Our results also have implications for the collective approach to household behavior developed by Chiappori (1992), Browning and Chiappori (1998), and Blundell et al. (2005, 2007). If a tax-benefit policy reform affects the feasible utilities of divorced mothers, and if the outside option to marriage is divorce, then it might also affect married couples indirectly by changing intra-household sharing rules so as to reflect the preferences of married mothers either more or less strongly. Finally, ambiguous effects of family policies have also been identified by noncooperative models of household decision-making (e.g., Konrad and Lommerud 1995; Chen and Wooley 2001). Our work, therefore, will extend such strands of research to divorced parents and their children.

Concerns about the well-being of children of divorced parents have also been raised by several recent theoretical (e.g., Chiappori and Weiss, 2006 and 2007; Chiappori et al., 2007) and empirical (e.g., Gruber 2004; Wolfers 2006; Stevenson and Wolfers 2006; Stevenson 2007) studies, which examine the role played by the legal environment surrounding the family in general and by divorce law in particular. Our work shares these concerns, although we focus on the changes in parental behavior that might be induced by reforms of the tax-benefit system rather than by other legal changes. This focus allows us to address (and possibly understand)

\footnotetext{
${ }^{5} \mathrm{~A}$ similar conclusion is reached in Roff (2008), which uses a noncooperative framework to analyze the child support and welfare participation decisions of never-married parents on welfare. Single mothers choose whether to exit welfare, report paternity and obtain a child support order. If child support orders are awarded, fathers choose whether to comply with them or not. Structural estimates show that high child support awards can lead to a reduction in child support payments from noncustodial fathers to custodial mothers.
} 
some of the unexpected or counterintuitive effects of welfare reform that have been documented, among others, by Harknett and Gennetian (2003), Clark-Kauffman et al. (2003), Bitler et al. (2005, 2006), Morris et al. (2007), Baker et al. (2008), Herbst and Tekin (2008), and Gregg et al. (2009). We shall link our main results, which are outlined in the next three sections, to such empirical findings in Section 6.

\section{The Basic Framework}

The goal of our analysis is to understand how changes in the tax-benefit system, and especially in in-work benefits (such as EITC and WFTC), affect the behavior of divorced parents. Consider a non-intact family that is comprised of a child, a custodial mother $m$, and a nonresident/noncustodial father $f$. Each parent $i(i=f, m)$ has preferences defined over private consumption, $x_{i}$, and child welfare, $C$. Child welfare depends on both childcare quality, $q$, and child good expenditures, $k$, and is produced according to

$$
C=F(k, q)=k^{a} q^{b}
$$

where the parameters $a$ and $b$ are such that $0<a<1,0<b<1$ and $a+b<1$ which implies that the function $F$ is strictly increasing in each of its arguments and is strictly concave. Parental preferences are represented by Cobb-Douglas utilities:

$$
U_{f}\left(x_{f}, C\right)=x_{f}^{\gamma_{f}} C^{1-\gamma_{f}} \quad \text { and } \quad U_{m}\left(x_{m}, C\right)=x_{m}^{\gamma_{m}} C^{1-\gamma_{m}}
$$

where $\gamma_{f}$ and $\gamma_{m}$, which represent the preference weights on own consumption for the father and the mother respectively, are assumed to be contained in the open unit interval. It is useful to define

$$
\alpha_{i}=a\left(1-\gamma_{i}\right) \quad \text { and } \quad \beta_{i}=b\left(1-\gamma_{i}\right)
$$

as parent $i$ 's $(i=f, m)$ productivity-weighted preferences over $k$ and $q$, respectively. Substituting (1) into (2) and using (3), the parent's utility functions can be re-written as

$$
U_{f}\left[x_{f}, F(k, q)\right]=x_{f}^{\gamma_{f}} k^{\alpha_{f}} q^{\beta_{f}} \quad \text { and } \quad U_{m}\left[x_{m}, F(k, q)\right]=x_{m}^{\gamma_{m}} k^{\alpha_{m}} q^{\beta_{m}}
$$

For simplicity (but also reflecting the prevailing norm in living arrangements among divorced parents), we assume that the mother has legal and physical custody of the child. Under this sole custody assumption, the mother controls both childcare quality $(q)$ and child good expenditures $(k)$, while the father cannot monitor his ex-spouse's resource allocation directly. The only way in which the father can affect $q$ and $k$ is through child support payments, $s$, which are transferred 
to the mother. The interactions we are interested in are those between the mother and the father. In the background, besides the child, there is however another inactive player, namely a welfarist government that may choose some key institutional variables, such as in-work benefit levels and childcare subsidies to daycare costs.

We envisage a two-stage game between $m$ and $f$, which unfolds as follows. In stage 1 , the father chooses the monetary level of child support, $s$, to transfer to the mother. Assuming that the father's labor supply is fixed and that he has income $\mathbf{y}>0, s$ lies in $[0, \mathbf{y}]$. In stage $2, s$ is received (and observed) by the mother. The mother, who has a unit of active time endowment, spends the fraction $l \in[0,1)$ of time working in the labor market and the remaining fraction $h=1-l$ in childcare activities. Having chosen $l$, the mother then decides on how to divide her after-tax income between private consumption, $x_{m}$, and child good expenditures, $k^{6}$

To keep our analysis simple, leisure decisions are not modeled. Thus, $h$ can be viewed as maternal time input used to produce childcare quality $q$. Specifically, we assume that $q$ is produced according to a technology that is linear in both the fraction of time the custodial mother spends with the child $(1-l)$ and the fraction of time the child is looked after by someone else while the mother works $(l)$. There is therefore an implicit equivalence between maternal hours of work and paid childcare, ${ }^{7}$ and these two inputs are assumed to be imperfect substitutes. Setting the marginal productivity (or quality) of maternal time to 1 and the quality of formal childcare to $\psi$, childcare quality $q$ is produced according to

$$
q=(1-l)+\psi l=1-\delta l
$$

where $\delta=1-\psi>0$ is a parameter that captures the difference between maternal childcare quality and the quality of childcare purchased in the market. In assuming $\delta>0$ we explicitly posit that, while purchased childcare services may contribute to child welfare, they are of inferior quality in comparison to maternal childcare. ${ }^{8}$

Since a working single mother must rely on childcare and if this must be paid for, ${ }^{9}$ she faces an effective wage which falls short of her after-tax wage by the hourly price of childcare.

\footnotetext{
${ }^{6}$ Del Boca and Flinn (1995) and Flinn (2000) also consider an environment in which decision making proceeds sequentially. This assumption simplifies our analysis. Notice, however, that all our main insights would also hold in the corresponding simultaneous-move game.

${ }^{7}$ This equivalence is imposed to ease the exposition of some results, without affecting our main insights. Indeed, all results are robust to using a linear relationship between hours of paid work and childcare, as supported by the empirical evidence presented in Duncan et al. (1995).

${ }^{8}$ Empirical research on the effect of nonmaternal care on child developmental and behavioral outcomes tends to document a strong negative relationship (e.g., Belsky 2001, NICHD-ECCRN 2003, Baker et al. 2008, and references therein). Negative formal childcare effects also emerge in the case of later child outcomes (e.g., Bernal and Keane 2008; Liu et al. 2008).

${ }^{9}$ Indeed, some in-work benefits - such as WFTC in the UK - entail additional tax credits when mothers use paid childcare services (e.g., those offered by registered daycare centers and childminders). Not allowing
} 
Formally, if we denote by $w>0$ the mother's hourly wage rate and by $p>0$ the hourly price of formal childcare, the mother's effective wage rate is

$$
\mathbf{w}=w(1-\tau)-p
$$

where $\tau$ is the marginal rate of income tax. The government might raise the mother's effective wage $\mathbf{w}$ by reducing the marginal rate of income tax (lower $\tau$ ) or by providing more generous childcare subsidies (lower $p$ ). The after-tax income of the mother is then

$$
\mathbf{w} l+B+s,
$$

where $B \geq 0$ denotes government transfers (e.g., income support, child benefit, and child tax credit) and $s$ is the child support payment from the noncustodial father. Throughout our analysis, we will maintain the following simplifying restriction on the model parameters:

\section{Assumption 1}

$$
0<\frac{\left(\alpha_{m}+\gamma_{m}\right) \mathbf{w}-\beta_{m} \delta B}{\mathbf{w} \delta\left(\alpha_{m}+\beta_{m}+\gamma_{m}\right)}<1
$$

This places a lower bound $(\underline{\mathbf{w}})$ and an upper bound $(\overline{\mathbf{w}})$ on the value of the mother's effective wage rate, w. ${ }^{10}$ As will become apparent later, the upper bound ensures that the mother's labor supply is less than 1, i.e., it rules out solutions in which the mother spends her entire time endowment working in the labor market. The lower bound guarantees that, in the absence of a positive child support payment from the noncustodial father, the mother would always find it optimal to participate in the labor market by choosing labor supply greater than 0 . The latter assumption not only enables us to simplify the analysis but is also justified by the goal of this work, which is focused on providing useful insights into the effects of tax-benefit policy changes on divorced parents' labor supply and child support decisions. ${ }^{11}$

\section{The Effect of Tax-Benefit Policy Reform on Divorced Parents' Behavior}

Having described the framework in which the two-stage game between $f$ and $m$ takes place, we now characterize its subgame-perfect equilibrium using standard backwards induction arguments. We then consider how changing the institutional parameters ( $B$ and $\mathbf{w})$ affects the equilibrium choices and describe the underlying welfare effects.

women to use on unpaid/informal childcare services (e.g., those offered by relatives and friends) may be slightly unrealistic, but allows our model to capture some salient aspects of recent tax-benefit policy reforms. Extending this framework to account for both types of childcare is an interesting exercise which is left for future research.

${ }^{10}$ These are $\underline{\mathbf{w}}=\delta \beta_{m} B /\left(\alpha_{m}+\gamma_{m}\right)$ and $\overline{\mathbf{w}}=\delta \beta_{m} B /\left[(1-\delta)\left(\alpha_{m}+\gamma_{m}\right)-\delta \beta_{m}\right]$, respectively.

${ }^{11}$ For women with wage rates below $\underline{\mathbf{w}}$, we are back to a setting similar to that in Weiss and Willis (1985) and Del Boca and Flinn (1995) which treats the custodian's labor supply decision and income as exogenous. In such an environment, the allocation of resources within non-intact families would be independent of policies aimed at increasing the (non-working) custodian's effective wage. 


\section{A. Mother's Decisions}

Fix an arbitrary child support payment $s \in[0, \mathbf{y}]$ made by the father in stage 1 . In stage 2, the custodial mother decides how to allocate her time between market work and childcare activities by choosing $l$, and then chooses how to allocate her after-tax income between private consumption, $x_{m}$, and expenditures on the child, $k$. It is useful to decompose the second stage into a step where the mother first makes her time allocation decision and then decides over her income allocation.

Consider first the budget allocation decision. The mother's after-tax income is $B+\mathbf{w} l+s$. Let $\pi_{x}$ denote her income share in private consumption $x_{m}$, and $\pi_{k}$ her income share in child goods $k$. Then, the mother's income allocation problem is

$$
\max _{\pi_{x}, \pi_{k}}\left[\pi_{x}(B+\mathbf{w} l+s)\right]^{\gamma_{m}}\left[\pi_{k}(B+\mathbf{w} l+s)\right]^{\alpha_{m}} q^{\beta_{m}}
$$

subject to $\pi_{x}+\pi_{k}=1 .^{12}$ Cobb-Douglas preferences imply constant expenditure shares, which in equilibrium are

$$
\pi_{x}^{e}=\frac{\gamma_{m}}{\alpha_{m}+\gamma_{m}} \equiv \pi_{x}^{*} \quad \text { and } \quad \pi_{k}^{e}=\frac{\alpha_{m}}{\alpha_{m}+\gamma_{m}} \equiv \pi_{k}^{*}
$$

Consider now the time allocation decision. Under (5), the mother's second stage time allocation problem is to solve

$$
\max _{0 \leqslant l<1}\left[\pi_{x}^{e}(B+\mathbf{w} l+s)\right]^{\gamma_{m}}\left[\pi_{k}^{e}(B+\mathbf{w} l+s)\right]^{\alpha_{m}}(1-\delta l)^{\beta_{m}}
$$

Since there may be a corner solution in which the mother decides not to participate in the labor market, define $\tilde{s}$ to be the child support payment that implicitly solves the mother's first-order condition when $l=0$. This is given by

$$
\tilde{s}=\frac{\left(\alpha_{m}+\gamma_{m}\right) \mathbf{w}-\beta_{m} \delta B}{\beta_{m} \delta}
$$

Note that under Assumption 1, $\tilde{s}>0$. The mother's time allocation decision in stage 2 is then described by the following:

Proposition 1 Suppose Assumption 1 holds. Given any arbitrary child support payment $s \in$ $[0, y]$ from the father, the mother's optimal choice of $l$ is:

(i) $l^{e}=0$, if $s \geqslant \tilde{s}$; or

\footnotetext{
${ }^{12}$ With Cobb-Douglas preferences, this problem is equivalent to choosing $\left(x_{m}, k\right)$ to maximize $U_{m}\left[x_{m}, F(k, q)\right]=x_{m}^{\gamma_{m}} k^{\alpha_{m}} q^{\beta_{m}}$ subject to the budget constraint $x_{m}+k=B+\mathbf{w} l+s$.
} 
(ii)

$$
l^{e}=\frac{\left(\alpha_{m}+\gamma_{m}\right) \mathbf{w}-\beta_{m} \delta(B+s)}{\mathbf{w} \delta\left(\alpha_{m}+\beta_{m}+\gamma_{m}\right)} \equiv l^{*}(s), \quad \text { if } \quad s<\tilde{s} .
$$

Therefore, mothers who receive a transfer above the threshold $\tilde{s}$ choose to be out of the labor market, while those who receive a transfer below $\tilde{s}$ choose to be in paid employment. Expression (12) reflects the trade-off between home-produced childcare quality and employment as a function of the father's support payment $s$ and the institutional parameters $B$ and $\mathbf{w}$. It can be easily verified that an increase in $s$ reduces the mother's labor supply. Intuitively, if the mother receives a relatively high child support transfer, she is willing to substitute work time in the market for childcare time at home, and this has a beneficial impact on childcare quality. An increase in w, instead, raises labor supply. The mother's demand functions for private consumption and child good expenditures satisfy standard properties: that is, they are increasing in $s, B$, and w. Finally, child welfare - which positively depends on child good expenditures and maternal time - is strictly increasing in $s$ and $B$. An increase in w, however, has an ambiguous effect on child welfare: while it increases child good expenditures, it also reduces the amount of time the child receives direct interaction with the mother.

\section{B. Father's Decision}

The father's budget constraint is $x_{f}=\mathbf{y}-s$. He is assumed to care not only about his own consumption but also about the welfare of his child. ${ }^{13}$ Child welfare, in turn, depends on child good expenditures, $k^{e}=\pi_{k}^{e}\left(B+\mathbf{w} l^{e}+s\right)$, and childcare quality, $q^{e}=1-\delta l^{e}$, which are controlled by the custodial mother. Thus, the father's first stage optimization problem is to solve

$$
\max _{0 \leqslant s \leqslant \mathbf{y}}(\mathbf{y}-s)^{\gamma_{f}}\left[\pi_{k}^{e}\left(B+\mathbf{w} l^{e}+s\right)\right]^{\alpha_{f}}\left(1-\delta l^{e}\right)^{\beta_{f}} .
$$

His decision is driven by the way in which child good expenditures and childcare quality vary with child support transfers. The following result, which is illustrated in Figure 1, characterizes the unique subgame perfect equilibrium of our model.

Proposition 2 Suppose Assumption 1 holds. Define:

$$
\bar{s}=\frac{\alpha_{f} \mathbf{y}-\gamma_{f} B}{\alpha_{f}+\gamma_{f}} \quad \text { and } \quad s^{*}=\frac{\delta\left(\alpha_{f}+\beta_{f}\right) \mathbf{y}-\gamma_{f}(\mathbf{w}+\delta B)}{\delta\left(\alpha_{f}+\beta_{f}+\gamma_{f}\right)} .
$$

Let $\overline{\mathbf{y}}(\mathbf{w})$ solve $s^{*}=\tilde{s}$; and let $\underline{\mathbf{y}}(\mathbf{w})$ solve $s^{*}=0$. Then, $\overline{\mathbf{y}}(\mathbf{w})>\underline{\mathbf{y}}(\mathbf{w})$ for all $\mathbf{w} \in(\underline{\mathbf{w}}, \overline{\mathbf{w}})$, and:

\footnotetext{
${ }^{13}$ Grogger and Karoly (2009) formulate an alternative model in which divorced fathers do not receive utility from child well-being.
} 


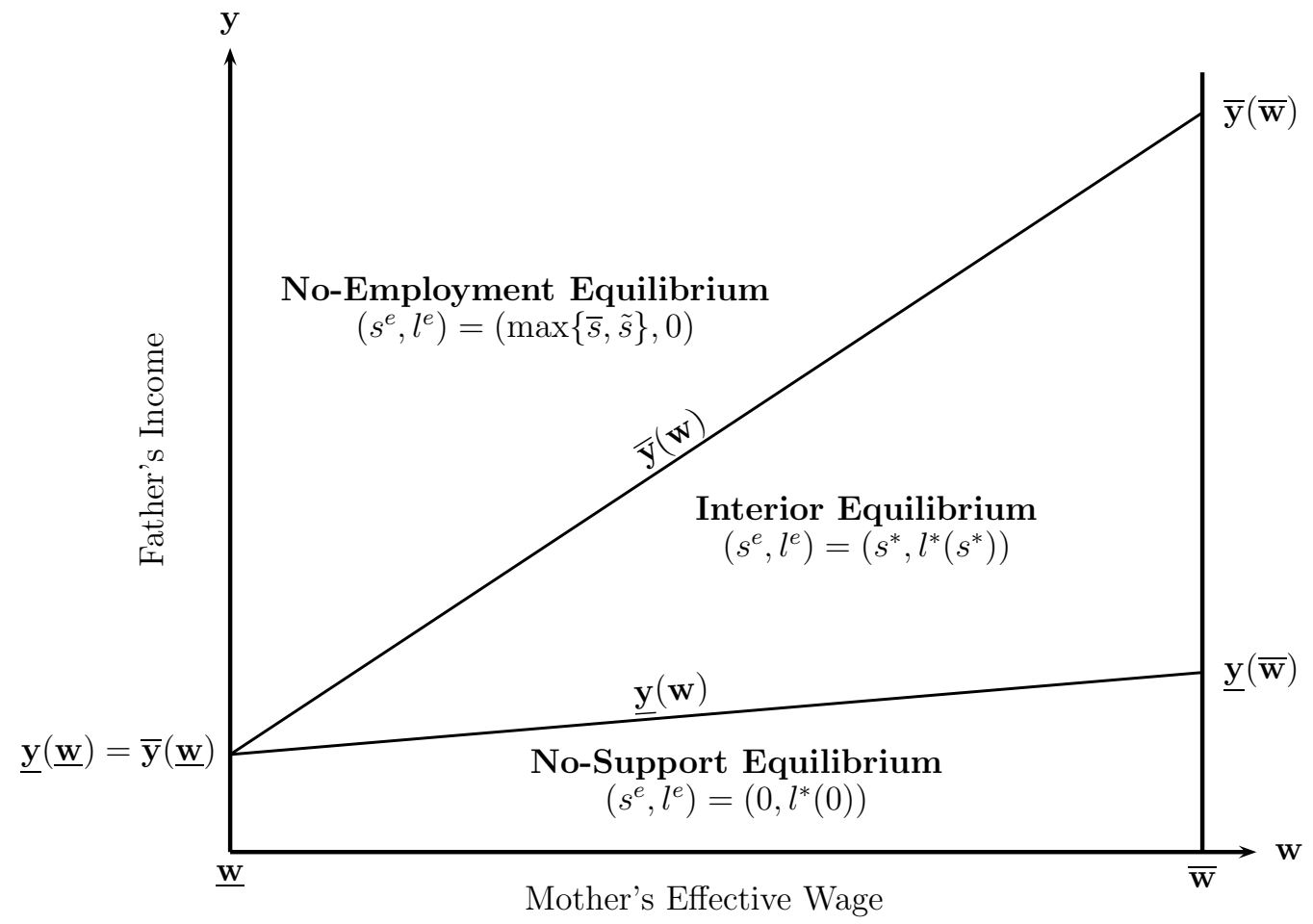

Figure 1: Equilibrium child support payment (father) and time allocation (mother) decisions

(i) if $\mathbf{y} \in(\mathbf{y}(\mathbf{w}), \overline{\mathbf{y}}(\mathbf{w}))$, the father's optimal support payment is $s^{e}=s^{*}$, and the mother's optimal labor supply is $l^{e}=l^{*}\left(s^{*}\right)$ ("interior equilibrium").

(ii) if $\mathbf{y} \geqslant \overline{\mathbf{y}}(\mathbf{w})$, the father's support payment is $s^{e}=\max \{\bar{s}, \tilde{s}\}$, and the mother's labor supply is $l^{e}=0$ ("no-employment equilibrium").

(iii) if $\mathbf{y} \leqslant \mathbf{y}(\mathbf{w})$, the father's support payment is $s^{e}=0$, and the mother's labor supply is $l^{e}=l^{*}(\overline{0)}$ ("no-support equilibrium").

In either (i), (ii), or (iii), the mother spends fractions $\pi_{x}^{e}=\pi_{x}^{*}$ and $\pi_{k}^{e}=\pi_{k}^{*}$ of her equilibrium after-tax income on private consumption and child goods, respectively.

There are, therefore, three types of equilibria. Consider an arbitrary value of $\mathbf{w}$ in the open interval $(\underline{\mathbf{w}}, \overline{\mathbf{w}})$. If the father's income is sufficiently high, $\mathbf{y} \geqslant \overline{\mathbf{y}}(\mathbf{w})$, we have a no-employment equilibrium: here, the child support payment made by the father, $s^{e}=\max \{\bar{s}, \tilde{s}\}$, is high enough to allow the mother to choose full-time parenting, so that $l^{e}=0$ (case $(i i)$ ). If the father's income instead is at an intermediate level, $\mathbf{y} \in(\underline{\mathbf{y}}(\mathbf{w}), \overline{\mathbf{y}}(\mathbf{w}))$, then we are at an interior equilibrium (case $(i)$ ): the child support payment made by the father, $s^{e}=s^{*}$, is positive but not large enough to enable the mother to spend all of her time looking after the child, and so she decides to supply a positive amount of labor to the market, namely $l^{e}=l^{*}\left(s^{*}\right)$. Finally, if the father's income is low, $\mathbf{y} \leqslant \underline{\mathbf{y}}(\mathbf{w})$, we have a no-support equilibrium (case (iii)): here, the 
father does not volunteer any child support payments, i.e., $s^{e}=0$, while the mother devotes a relatively large proportion of her time to market work, $l^{e}=l^{*}(0){ }^{14}$

The main aim of this study is to develop an understanding of the interplay between taxbenefit policy reform and the behavior of divorced parents in terms of child support payments, time allocated to work and parenting, and child good expenditures. Marginal changes in taxbenefit policies have no direct effect on mothers' labor supply decisions in the no-employment equilibrium, and so we will not focus on it. In addition, since marginal policy changes have no impact on the behavior of divorced fathers in the no-support equilibrium, we will not focus on it either. ${ }^{15}$ Therefore, we focus mainly on the interior equilibrium in which neither parent is bound by non-negativity constraints. The two most interesting features of this interior equilibrium are its efficiency properties and the comparative statics with respect to the tax-benefit parameters ( $B$ and $\mathbf{w})$, to which we now turn.

\section{Efficiency Properties of the Equilibrium}

A key aspect of our model is that child well-being is a public good from the point of view of both parents, although only the custodial parent decides on childcare quality and child good expenditures. In our setting, there is no self-enforcing mechanism that induces the custodian to internalize the impact of her choices on the noncustodian. In particular, noncooperative behavior implies that the ex-spouses cannot negotiate and then commit to binding and costlessly enforceable agreements. As a consequence, they fail to achieve a socially-efficient allocation of their resources. The following proposition describes the distortions that arise in this framework.

Proposition 3 In an interior equilibrium, where $s^{e}=s^{*}, l^{e}=l^{*}\left(s^{*}\right)$ and $\pi_{k}^{e}=\pi_{k}^{*}$, each of (i) a marginal increase in $\pi_{k}$, (ii) a marginal reduction in l, and (iii) a marginal increase in $s$ would lead to a Pareto improvement.

The interior equilibrium suffers from three inefficiencies. On the custodial side, the amount spent on child goods is not efficient, since the mother does not internalize the effect of her income allocation on the father. This is a standard problem which has been discussed before (Weiss and Willis 1985; Flinn 2000). However, in addition to spending an inefficiently low amount on child goods, the mother also supplies an inefficiently high amount of labor time to the market, that is, she spends too much time at work and too little on childcare activities. On the noncustodial side, anticipating that the mother will spend too little on child goods

\footnotetext{
${ }^{14}$ From (12), it is easy to check that, in the no-support equilibrium, the mother works more than in the interior equilibrium, i.e., $l^{*}(0) \geq l^{*}\left(s^{*}\right)$.

${ }^{15}$ We will, however, in the next section briefly comment on some comparative static results that would be obtained in the no-support equilibrium.
} 
and work too much in the labor market, the father offers inadequate child support payments. Essentially, the father cannot monitor time and income allocations of his former spouse; thus, through his child support transfer, he tries to influence the mother to spend more money on child goods and substitute hours of parenting for hours of paid work. But because the mother only spends a fraction of the transfer received from the father on child goods, and because she supplies more than the socially optimal amount of labor, the father does not fully capture the social marginal return from his child support payment. Therefore, his transfer is less than the social optimum.

\section{Equilibrium Comparative Statics}

So far we have characterized parents' decisions given the tax policy parameters, $B$ and w. We now consider how changes in such parameters affect those choices and illustrate the corresponding welfare effects. As the choices in the interior equilibrium depend on $B$ and w (see expressions (12) and (14)), our notation will have to acknowledge this explicitly. The father's optimal transfer then is denoted $s^{e}=s^{*}(B, \mathbf{w})$, and the mother's optimal labor supply is $l^{e}=l^{*}\left(B, \mathbf{w}, s^{*}(B, \mathbf{w})\right)$. We examine the effects of a policy reform that operates through two distinct channels. The first involves a more generous government transfer to the custodial parent (higher $B$ ); the second implies an increase in the custodian's effective wage w, which can be achieved either through greater childcare subsidies (lower $p$ ) or through a reduction in the marginal rate of income tax (lower $\tau$ ).

We begin with the effects on the father's child support decision with the following:

Proposition 4 In the interior equilibrium, where $l^{e}=l^{*}\left(B, \mathbf{w}, s^{*}(B, \mathbf{w})\right)$ and $s^{e}=s^{*}(B, \mathbf{w})$, the noncustodian's child support payment is (i) strictly decreasing in $B$, and (ii) strictly decreasing in $\mathbf{w}$.

This result suggests that greater $B$ and $\mathbf{w}$ optimally induce the father to reduce his child support payment $s^{*}(B, \mathbf{w})$. Thus, policies that increase government transfers and/or the effective wage received by the custodial parent will crowd out child support transfers from the noncustodian. Greater government transfers paid to the mother (part ( $i$ ) of Proposition 4) have the same positive effect on her decision environment as an increase in the support payment by the noncustodial father: that is, it induces the mother to spend more financial resources on child goods, and to substitute hours of childcare at home for hours of work in the market. But this, in turn, implies that the father can respond to the original increase in welfare payments by reducing his child support transfer without compromising child welfare.

Slightly more subtle are the issues related to the impact of an increase in the mother's 
effective wage (part (ii) of Proposition 4). It is useful to separate this into two distinct effects. First, holding the mother's labor supply constant, an increase in w raises her after-tax income, which translates into an increase in child good expenditures. Again, this in turn allows the father to reduce his transfers without jeopardizing child welfare. In fact, it is as if father's income increased, allowing him to expand his private consumption at the expense of child support payment. Second, an increase in w leads the mother to increase her labor supply. This will have two opposite effects. On the one hand, it induces the father to increase his child support payment in an attempt to offset the increase in mother's labor supply. On the other hand, it permits the father to reduce his child support transfers because the increase in mother's labor supply is accompanied by an increase in her income and thus in child good expenditures allowing the father to substitute his private consumption for child support. In our framework, the latter effect strictly dominates the former. Therefore, the net total effect of an increase in mother's effective wage is to induce the father to increase his private consumption and, accordingly, reduce his child support payment.

This substitution from child support to private consumption on the noncustodial side can have repercussions on both child welfare and parents' well-being. Before looking at this issue, we first ascertain the effects of the tax-benefit reform on the mother's labor supply decision. For this, we have:

Proposition 5 In the interior equilibrium, where $l^{e}=l^{*}\left(B, \mathbf{w}, s^{*}(B, \mathbf{w})\right)$ and $s^{e}=s^{*}(B, \mathbf{w})$, the custodian's labor supply is (i) strictly decreasing in B, and (ii) strictly increasing in $\mathbf{w}$.

In our model, the interior equilibrium is characterized by the mother choosing inefficiently high levels of labor supply. Proposition 5 indicates that, ceteris paribus, an increase in the level of government transfers received by the mother will reduce her labor supply, mitigating the inefficiency of over-employment (part $(i)$ ). There are two opposite effects at work here. On the one hand, we have a standard income effect of transfer receipt: an increase in $B$ makes the mother richer, and this allows her to reduce her labor supply and spend more time at home with the child. On the other hand, we have an indirect, or strategic, effect: an increase in government transfers paid to the mother leads the father to reduce his child support payments, and this in turn increases the mother's labor supply. The income effect is larger than the strategic effect in absolute value, and thus the mother's labor supply is decreasing in $B$. An increase in the mother's effective wage, in contrast, increases her labor supply, reinforcing the inefficiency due to over-employment (part (ii) of Proposition 5). This relationship, again, is driven by two effects which, in this case, work in the same direction. There is a direct substitution effect: an increase in the effective wage rate increases the mother's labor supply since it pushes up the 
opportunity cost of staying at home and looking after the child. ${ }^{16}$ Besides this direct effect, there is also a strategic "multiplier" effect. This arises because an increase in the mother's effective wage induces the father to reduce child support payments, and this reduction further magnifies the proportion of time the mother chooses to spend in the labor market.

\section{E. Welfare Effects}

We now consider the welfare effects generated by the type of policy reform analyzed above. We are interested not only in how the reform affects the equilibrium utility of mother and father, but also in its impact on equilibrium child welfare. The questions we address are: What welfare effects would arise from increasing the government transfers paid to the mother? And what are the welfare effects of an increase in the mother's effective wage rate? The answer to the first question is encapsulated in

Proposition 6 In the interior equilibrium, an increase in $B$ would (i) raise the utilities of custodial and noncustodial parents and (ii) increase child welfare.

This result is perhaps unsurprising. While an increase in government transfers paid to the mother reduces the child support payment from the father, it nevertheless allows the mother to reduce her labor supply and spend more financial resources on child goods, which unambiguously raises child welfare and increases both parents' utilities.

The answer to the second question is more surprising. Letting $\delta(a+b) /[(1-\delta)+\delta(a+b)] \equiv \bar{\gamma}$, this is given in

Proposition 7 In the interior equilibrium, if the parents' preference parameters are such that $\gamma_{f} \geqslant \bar{\gamma}$ and $\gamma_{m} \geqslant \bar{\gamma}$, then an increase in $\mathbf{w}$ would (i) lower the utilities of custodial and noncustodial parents and (ii) reduce child welfare.

We ought to point out that the premises of this proposition (i.e., the assumption on the preference parameters $\gamma_{f}$ and $\gamma_{m}$ ) impose sufficient conditions. In fact, there are weaker sufficient conditions — which allow for $\gamma_{f}<\bar{\gamma}$ and/or $\gamma_{m}<\bar{\gamma}$ - under which this finding holds too (see Proposition 8 below). The result here implies that, if private consumption has a sufficiently large weight in parents' utilities, then an increase in the effective wage of the mother (through either a greater childcare subsidy or a lower income tax rate) would unambiguously reduce child welfare and lower the utility of both parents. This offers us an insight which so

\footnotetext{
${ }^{16} \mathrm{An}$ increase in the effective wage also makes the mother richer, and this reduces her labor supply. In our setting, however, this income effect is strictly dominated by the substitution effect described in the text. This is simply the result of our choice of the Cobb Douglas functional form for parental preferences. However, that the substitution effects dominate labor supply decisions holds more generally for any forward-sloping labor supply function.
} 
far has been overlooked in the literature: a tax-benefit policy that also subsidizes households' childcare expenditures or lowers marginal income tax rates faced by low-income working single parents and their children could worsen their well-being.

To see this, notice that we can reformulate the father's problem of Section 4.B as a choice between private consumption and child welfare. As long as the mother supplies a positive fraction of her time in paid work, the father's problem can be rewritten as:

$$
\begin{gathered}
\max _{C \geqslant \underline{C}} U_{f}=[(\mathbf{y}+\mathbf{w} / \delta+B)-\rho(\mathbf{w}) \mu(C)]^{\gamma_{f}} C^{1-\gamma_{f}}, \\
\text { where } \rho(\mathbf{w})=\frac{\left(\alpha_{m}+\beta_{m}+\gamma_{m}\right)}{\delta}\left[\left(\frac{\delta}{\alpha_{m}}\right)^{a}\left(\frac{\mathbf{w}}{\beta_{m}}\right)^{b}\right]^{\frac{1}{a+b}} \text { and } \mu(C)=C^{\frac{1}{a+b}} .
\end{gathered}
$$

Thus, the father's decision boils down to choosing between child welfare and private consumption as if he had effective money income $\mathbf{y}+\mathbf{w} / \delta+B$ and faced a non-linear price schedule for child welfare, $\rho(\mathbf{w}) \mu(C)$, which depends on the mother's effective wage and the preference parameters of her utility function. ${ }^{17}$ In his decision, the father takes into account the fact that his former spouse, without having to rely on his transfer, would guarantee a minimum level of child welfare $\underline{C}(\mathbf{w})$, where $\mathrm{e}^{18}$

$$
\underline{C}(\mathbf{w})=\left[\frac{\pi_{k}^{*}\left(\alpha_{m}+\gamma_{m}\right)}{\delta}\right]^{a}\left(\frac{\beta_{m}}{\mathbf{w}}\right)^{b}\left(\frac{\mathbf{w}+\delta B}{\alpha_{m}+\beta_{m}+\gamma_{m}}\right)^{a+b} .
$$

In this context, an increase in the mother's effective wage rate entails three changes that are relevant to the father's decision problem. First, it raises his money income $\mathbf{y}+\mathbf{w} / \delta+B$; second, it raises the implicit price for child welfare $\rho(\mathbf{w})$; third, it lowers the minimum amount of child welfare $\underline{C}(\mathbf{w})$ the father can obtain when he does not make any child support payment. As illustrated in Figure 2, at an interior equilibrium these changes produce three effects on the father's decision environment:

(a) a money income effect (MIE): holding $\rho(\mathbf{w})$ constant, an increase in $\mathbf{w}$ raises the father's money income, giving him an incentive to increase his private consumption at the expense of child support transfers. Intuitively, if we hold the mother's labor supply constant, an

${ }^{17}$ If child welfare is evaluated at $\pi_{k}^{e}=\pi_{k}^{*}$ and $l^{e}=l^{*}(s)$, we obtain

$$
C=\left[\frac{\pi_{k}^{*}\left(\alpha_{m}+\gamma_{m}\right)}{\delta}\right]^{a}\left(\frac{\beta_{m}}{\mathbf{w}}\right)^{b}\left(\frac{\mathbf{w}+\delta(B+s)}{\alpha_{m}+\beta_{m}+\gamma_{m}}\right)^{a+b}
$$

By inverting the above expression we obtain $s=\rho(\mathbf{w}) \mu(C)-\mathbf{w} / \delta-B$. It follows that the father's private consumption can be written as $x_{f}=\mathbf{y}-s=(\mathbf{y}+\mathbf{w} / \delta+B)-\rho(\mathbf{w}) \mu(C)$.

${ }^{18}$ The requirement $C \geqslant \underline{C}$ is therefore the analogue of the constraint $s \geqslant 0$ in the optimization of Section 4 .B and underlying Proposition 2 (see equation (14)). 


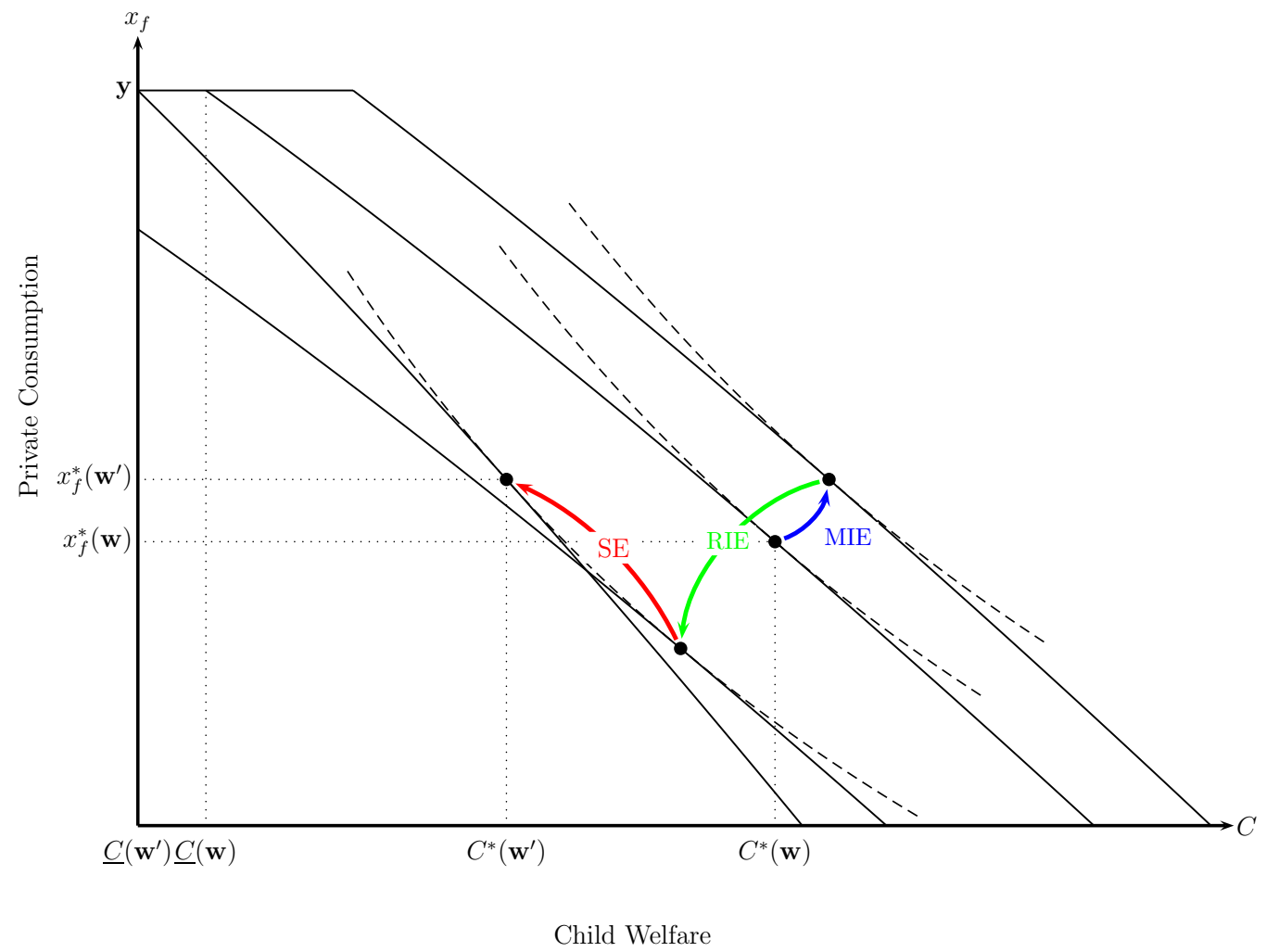

Figure 2: The effects of an increase in the mother's effective wage from $\mathbf{w}$ to $\mathbf{w}^{\prime}$

increase in $\mathbf{w}$ raises her after-tax income, and this increases child good expenditures and child welfare; this then yields an increase in the father's effective money income, inducing the father to increase his private consumption and cut child support.

(b) a real income effect (RIE): allowing now $\rho(\mathbf{w})$ to adjust, an increase in $\mathbf{w}$ raises the implicit price of child welfare as it induces the mother to work more; this in turn reduces the father's real income which leads to a reduction in his private consumption and to an increase in child support payments to the mother in the attempt to mitigate the increase in her labor supply.

(c) a substitution effect (SE): an increase in $\mathbf{w}$ causes the implicit price of child welfare to go up, thereby increasing the relative attractiveness of private consumption; this induces the father to substitute private consumption for child welfare (i.e., reduce support payments to the mother); the utility of the father is unaffected but child welfare is reduced.

The figure also illustrates that the total effect of an increase in $\mathbf{w}$ is to increase the father's private consumption (with the corresponding reduction in child support payments) and to lower child welfare. This last reduction is driven by the greater labor supply of the mother, which 

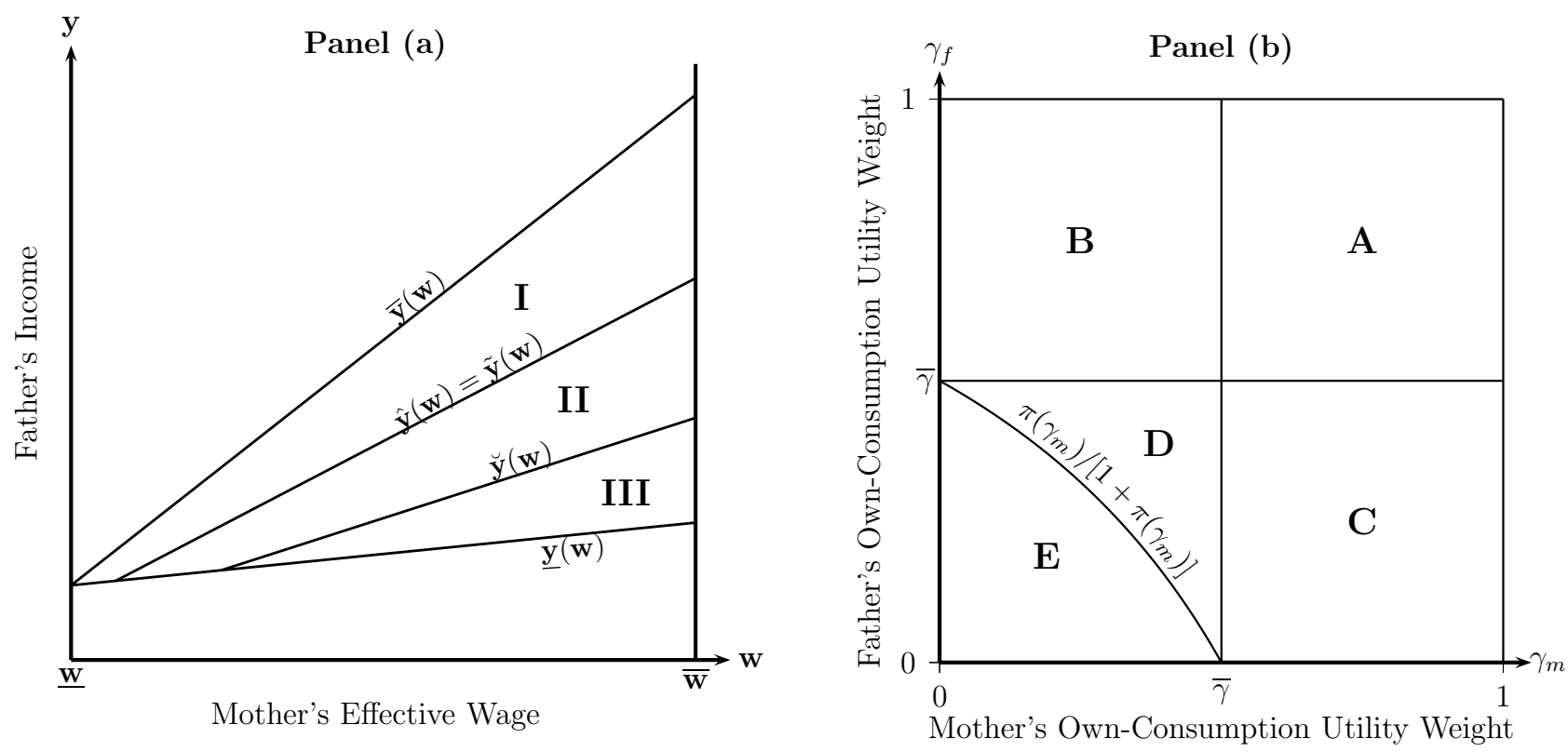

Figure 3: The effects of an increase in $\mathbf{w}$ on child and parental welfare

itself is the net result of the direct substitution effect (i.e., the opportunity cost of staying home goes up) and the strategic multiplier effect (i.e., the response to smaller child support from the father) described in the previous subsection.

Up until now we have considered the welfare effects of increasing the effective wage earned by the mother under the assumption that parents' own-consumption utility weights are sufficiently high $\left(\gamma_{f} \geqslant \bar{\gamma}\right.$ and $\left.\gamma_{m} \geqslant \bar{\gamma}\right)$. These results may continue to hold even when parents' ownconsumption utility weights are lower (e.g., $\gamma_{f}<\bar{\gamma}$ and/or $\gamma_{m}<\bar{\gamma}$ ). The set of parameter values in the $(\mathbf{y}, \mathbf{w})$-space for which this occurs is described in the following

Proposition 8 Let

$$
\hat{\mathbf{y}}(\mathbf{w})=\frac{\left(\alpha_{f}+\gamma_{f}\right) \mathbf{w}-\beta_{f} \delta B}{\beta_{f} \delta} \quad \text { and } \quad \tilde{\mathbf{y}}(\mathbf{w})=\frac{\left(\alpha_{m}+\gamma_{m}\right) \mathbf{w}-\beta_{m} \delta B}{\beta_{m} \delta} .
$$

If the model parameters are such that $\mathbf{y}>\max \{\hat{\mathbf{y}}(\mathbf{w}), \tilde{\mathbf{y}}(\mathbf{w})\}$, then an increase in the effective wage $\mathbf{w}$ would (i) lower the utility of custodial and noncustodial parents and (ii) reduce child well-being even if $\gamma_{f}<\bar{\gamma}$ and/or $\gamma_{m}<\bar{\gamma}$.

Figure 3 illustrates the effects of an increase in $\mathbf{w}$ on child and parental welfare in general terms. Panel (a) plots the father's income against the mother's effective wage. ${ }^{19}$ Panel (b), instead, plots the own-consumption utility weight of the father against that of the mother. Proposition 7 shows that if parents' preference parameters are such that $\gamma_{f} \geqslant \bar{\gamma}$ and $\gamma_{m} \geqslant \bar{\gamma}$ (region A

\footnotetext{
${ }^{19}$ For ease of exposition, the figure assumes $\gamma_{f}=\gamma_{m}$. This assumption implies that $\hat{\mathbf{y}}(\mathbf{w})=\tilde{\mathbf{y}}(\mathbf{w})$. Notice, however, that $\hat{\mathbf{y}}(\mathbf{w})$ will be larger (respectively, smaller) than $\tilde{\mathbf{y}}(\mathbf{w})$ if $\gamma_{f}>\gamma_{m}$ (respectively, if $\gamma_{f}<\gamma_{m}$ ).
} 
in panel (b)), then an increase in w would reduce child welfare and lower the utility of both parents for all $(\mathbf{y}, \mathbf{w})$-combinations that give rise to an interior equilibrium (regions I, II, and III in panel (a)). ${ }^{20}$ Proposition 8 establishes that, even if $\gamma_{f}<\bar{\gamma}$ and/or $\gamma_{m}<\bar{\gamma}$ (regions B to E), an increase in $\mathbf{w}$ would continue to reduce child welfare and lower the utility of both parents as long as the father's income and the mother's wage are such that $\mathbf{y}>\max \{\hat{\mathbf{y}}(\mathbf{w}), \tilde{\mathbf{y}}(\mathbf{w})\}$ (region I in panel (a)). Therefore, even if private consumption carries relatively little weight in parents' preferences, as long as the income of the noncustodial parent is sufficiently high, an increase in the mother's effective wage will have negative welfare consequences for all parties involved: the child, the custodial mother, and the noncustodial father.

It is important to underline that an increase in $\mathbf{w}$ will not always reduce the welfare of all parties. Our next step is to discuss configurations of parameter values for which one of the parties would be made better off. If parents' preference parameters are such that $\gamma_{f} \geqslant \bar{\gamma}$ and $\gamma_{m}<\bar{\gamma}$ (as in region B), an increase in w would reduce child welfare and lower the mother's utility; but the father will experience an increase in utility provided the model parameters are such that $\mathbf{y}<\hat{\mathbf{y}}(\mathbf{w})$ (as in regions II and III, panel (a)). Thus, if private consumption carries less weight in the mother's utility function than in the father's, and the father's income is sufficiently low, an increase in w would benefit the mother while hurting both the father and the child. If the preference parameters instead are such that $\gamma_{f}<\bar{\gamma}$ and $\gamma_{m} \geqslant \bar{\gamma}$ (as in region $\mathrm{C}$ ), an increase in $\mathbf{w}$ would reduce both child well-being and the father's utility; but the mother will experience an increase in utility provided that $\mathbf{y}<\tilde{\mathbf{y}}(\mathbf{w})$ (regions II and III). Perhaps surprisingly, there is also a case in which an increase in $\mathbf{w}$ lifts the utility levels of both parents, while reducing child welfare. This occurs if either $\pi\left(\gamma_{m}\right) /\left[1+\pi\left(\gamma_{m}\right)\right]<\gamma_{f}<\bar{\gamma}$ and $\gamma_{m}<\bar{\gamma}$ (region D), ${ }^{21}$ and $\mathbf{y}<\min \{\hat{\mathbf{y}}(\mathbf{w}), \tilde{\mathbf{y}}(\mathbf{w})\}$ (regions II and III, panel (a)); or if $\gamma_{f}<\bar{\gamma}$ and $\gamma_{m}<\bar{\gamma}$ (regions D and E) and $\breve{\mathbf{y}}(\mathbf{w})<\mathbf{y}<\min \{\hat{\mathbf{y}}(\mathbf{w}), \tilde{\mathbf{y}}(\mathbf{w})\}$ (region II, panel (a)).

The final result of this section completes the picture by describing the set of parameter values for which all parties involved would benefit from an increase in the effective wage of the custodial parent. This is given in

\section{Proposition 9 Let}

$$
\breve{\mathbf{y}}(\mathbf{w})=\frac{a \mathbf{w}-b \delta B}{b \delta} \quad \text { and } \quad \pi\left(\gamma_{m}\right)=\frac{(a+b)\left[\delta\left(\alpha_{m}+\beta_{m}\right)-(1-\delta) \gamma_{m}\right]}{(1-\delta)\left[\alpha_{m}+\beta_{m}+\gamma_{m}\right]} .
$$

If the model parameters are such that $\mathbf{y}<\breve{\mathbf{y}}(\mathbf{w})$ and $\gamma_{f}<\pi\left(\gamma_{m}\right) /\left[1+\pi\left(\gamma_{m}\right)\right]$, then an increase in the effective wage $\mathbf{w}$ would (i) raise the utility of both custodial and noncustodial parents and (ii) increase child well-being.

\footnotetext{
${ }^{20}$ As shown in Proposition 2 values outside of these regions do not correspond to an interior equilibrium.

${ }^{21}$ The function $\pi\left(\gamma_{m}\right)$ is explicitly defined in Proposition 9.
} 
Two conditions must be satisfied if an increase in $\mathbf{w}$ is to have a positive effect on child and parental well-being. Not only is it necessary that private consumption carries relatively little weight in both parents' preferences (region E), but also the noncustodial father must have a sufficiently low income (region III). Thus, policies that increase the effective wage of custodians are predicted to have positive welfare effects only for low-income divorced parents who value their private consumption relatively little viz-à-viz child well-being.

In sum, we have presented a comprehensive analysis of the effects of tax-benefit reform on the welfare of divorced parents and their children. Our results suggest that programs that increase the effective wage of custodial parents, either through lower marginal income tax rates or (as generally promoted with in-work benefit programs) through higher childcare subsidies, may have unexpected, possibly undesirable, welfare effects amongst divorced families. When parents' own-consumption utility weights are sufficiently high, such reforms may yield a decline in child and parental welfare. This result continues to hold even when private consumption carries little weight in parental preferences as long as the noncustodian enjoys a relatively high income. Only when the noncustodial parent has a low income will we see positive welfare effects, provided that parental preferences for own consumption are sufficiently weak.

Remark. Our discussion so far has focused on the negative welfare effects generated by policy reforms in the interior equilibrium of our model. By contrast, in the no-support equilibrium (see Proposition 2 and Figure 1), such reforms are less likely to yield declines in child and parental well-being. Intuitively, this is because an increase in the effective wage of custodial parents would no longer lead to a strategic multiplier effect, i.e., it would no longer induce the noncustodial parents to further reduce child support payments. As a consequence, the aggravation of the inefficiency due to over-employment is less severe in the no-support equilibrium than in the interior equilibrium. Formally, in the no-support equilibrium an increase in w would unambiguously raise the utility of the custodial mother. Moreover, if the model parameters are such that $\gamma_{m}<\bar{\gamma}$ (i.e., the mother's own-consumption utility weight is sufficiently low) and $\mathbf{w}>\tilde{\mathbf{w}}$ (i.e., the mother's wage is sufficiently high), ${ }^{22}$ then an increase in w would also raise the utility of the noncustodial father and increase child well-being. Conversely, if $\gamma_{m}>\bar{\gamma}$, or if $\gamma_{m}<\bar{\gamma}$ and $\mathbf{w}<\tilde{\mathbf{w}}$, then an increase in $\mathbf{w}$ would lower the utility of the noncustodial father and reduce child welfare.

\footnotetext{
${ }^{22}$ Here, $\tilde{\mathbf{w}}=b \delta B / a$. It is readily checked that $\tilde{\mathbf{w}} \in(\underline{\mathbf{w}}, \overline{\mathbf{w}})$ for all $\gamma_{m}<\bar{\gamma}$.
} 


\section{Extensions}

We now consider some useful extensions of our basic model. After this, we shall use our main results to interpret a wide range of findings that have emerged in the empirical literature.

\section{A. Child Support Orders and the Issue of Compliance}

In the model of Section 4, the government exogenously sets $B$ and $\tau$ and may choose to subsidize the purchase of formal childcare by varying its unit price $p$. But it does not influence child support transfers through, for instance, a system of court-mandated awards. To examine whether or not our earlier results change in an environment in which divorced parents face child support orders, we modify the noncustodial father's preferences in the way proposed by Del Boca and Flinn (1995) as follows:

$$
U_{f}\left[x_{f}, F(k, q), \theta\right]=x_{f}^{\gamma_{f}} k^{\alpha_{f}} q^{\beta_{f}}-\theta I\left[s<s^{o}\right]
$$

where $s^{o}>0$ is a court-mandated child support order and $I[\cdot]$ is an indicator function. ${ }^{23}$ The father pays a fixed cost, $\theta$, if he does not fully comply with the court order. But if his child support payment meets or exceeds the order, then the cost is avoided. Recall that the father's voluntary child support payment is given by

$$
s^{e}=\left\{\begin{array}{cl}
\max \{\bar{s}, \tilde{s}\} & \text { if } \mathbf{y} \geqslant \overline{\mathbf{y}}(\mathbf{w}) \\
s^{*} & \text { if } \mathbf{y} \in(\underline{\mathbf{y}}(\mathbf{w}), \overline{\mathbf{y}}(\mathbf{w})) \\
0 & \text { if } \mathbf{y} \leqslant \underline{\mathbf{y}}(\mathbf{w}),
\end{array}\right.
$$

where $\left(s^{*}, \bar{s}, \tilde{s}\right)$ and $(\underline{\mathbf{y}}(\mathbf{w}), \overline{\mathbf{y}}(\mathbf{w}))$ are defined in (11) and Proposition 2.

Consider the father's decision of whether or not to comply with the court order as a function of $\mathbf{y}$ and $\theta$, and assume $s^{o}<\tilde{s}$. This restriction ensures that the child support order — if fully complied with - is such that it is optimal for the mother to supply a positive fraction of her time to the labor market. With these ingredients, we can identify five different types of compliance behavior. Figure 4 describes these cases as a function of $\mathbf{y}$ and $\theta$.

In the previous section we have established that when the father's income $\mathbf{y}$ exceeds the threshold $\underline{\mathbf{y}}(\mathbf{w})$ the father will voluntarily make a positive child support payment to his former spouse. If, additionally, his voluntary payment $s^{*}$ is greater or equal to $s^{o}$, then the court order does not bind his transfer behavior. This is the case of overcompliance. Let $\mathbf{y}^{+}(\mathbf{w})$ be the

\footnotetext{
${ }^{23}$ For simplicity, we assume that the court-mandated order $s^{o}$ is independent of the father's income. However, our analysis would also go through under the alternative assumption that the father has to pay a fixed percentage of his income to the mother.
} 


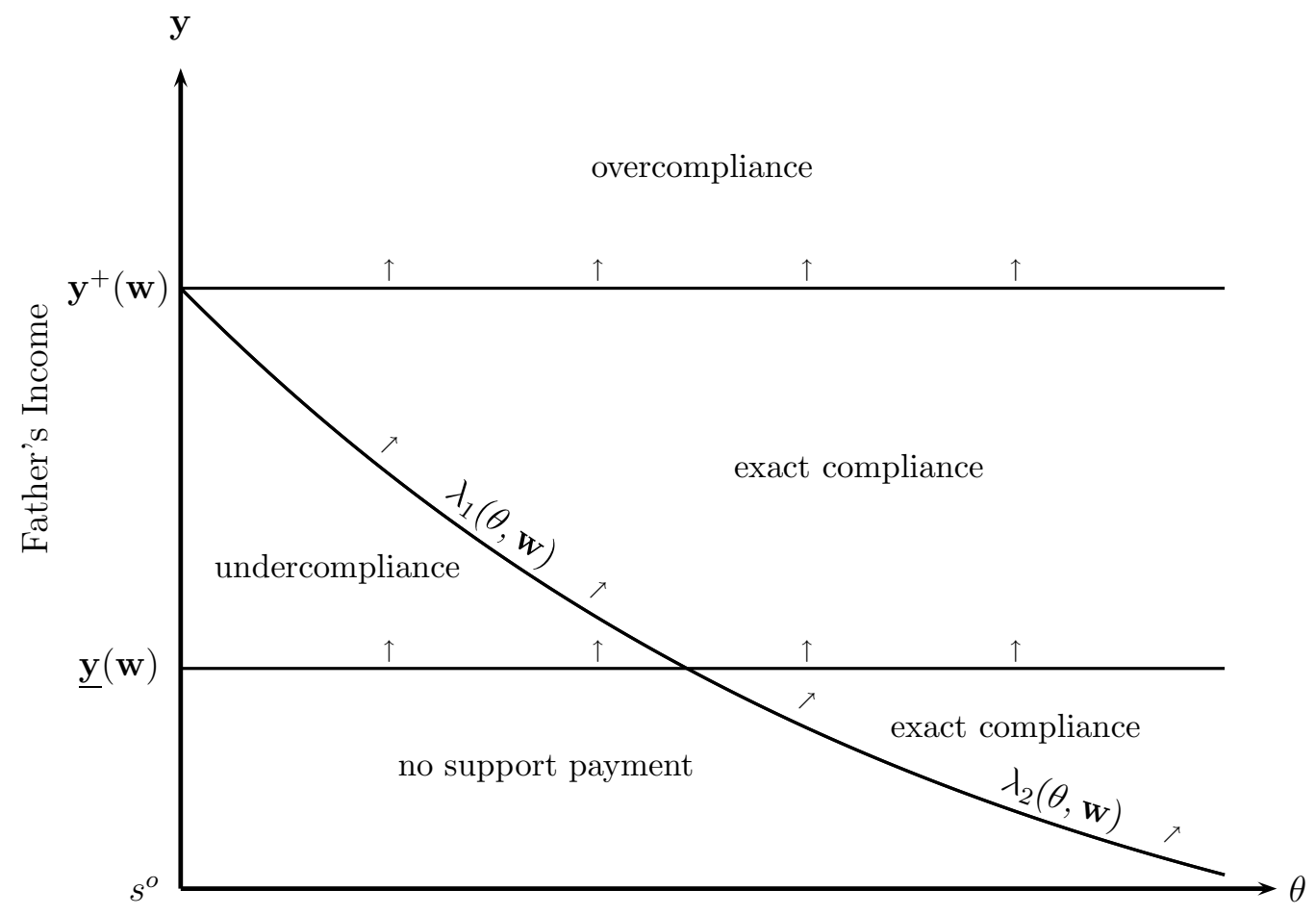

Cost of Noncompliance

Figure 4: Tax-benefit policy reform and compliance with child support orders (Note: The arrows show the effect of an increase in $\mathbf{w}$ )

value of the father's income for which the voluntary payment $s^{*}$ is exactly equal to the court order $s^{o} \cdot{ }^{24}$ Clearly, for the father to choose to be overcompliant, his income must be more than $\mathbf{y}^{+}(\mathbf{w})$.

Consider now the case in which the father's income is less than $\mathbf{y}^{+}(\mathbf{w})$ but more than $\underline{\mathbf{y}}(\mathbf{w})$. In this case, the father will again make a voluntary transfer to the mother, although $s^{*}$ will not be above the court order $s^{o}$. The father then has two options: he can either choose undercompliance by making his optimal voluntary transfer $s^{*}$ and incurring the cost $\theta$; or choose exact compliance by paying the order $s^{o}$ and avoiding the $\operatorname{cost} \theta$. Let $\lambda_{1}(\theta, \mathbf{w})$ be the value of $\mathbf{y}$ which equates the utility value of undercompliance to the utility value of exact compliance. $^{25}$ It then follows that a noncustodian with income between $\underline{\mathbf{y}}(\mathbf{w})$ and $\mathbf{y}^{+}(\mathbf{w})$ will

${ }^{24}$ Equating $s^{*}$ (see equation (14)) to $s^{o}$ and solving for $\mathbf{y}$, it follows that

$$
\mathbf{y}^{+}(\mathbf{w})=\frac{\gamma_{f}(\mathbf{w}+\delta B)+s^{o} \delta\left(\alpha_{f}+\beta_{f}+\gamma_{f}\right)}{\delta\left(\alpha_{f}+\beta_{f}\right)} .
$$

${ }^{25}$ Formally, $\lambda_{1}(\theta, \mathbf{w})$ implicitly solves

$$
\left(\mathbf{y}-s^{*}\right)^{\gamma_{f}}\left[\pi_{k}^{e}\left(B+\mathbf{w} l^{*}\left(s^{*}\right)+s^{*}\right)\right]^{\alpha_{f}}\left[1-\delta l^{*}\left(s^{*}\right)\right]^{\beta_{f}}-\theta=\left(\mathbf{y}-s^{o}\right)^{\gamma_{f}}\left[\pi_{k}^{e}\left(B+\mathbf{w} l^{*}\left(s^{o}\right)+s^{o}\right)\right]^{\alpha_{f}}\left[1-\delta l^{*}\left(s^{o}\right)\right]^{\beta_{f}} .
$$


choose undercompliance if $\mathbf{y}<\lambda_{1}(\theta, \mathbf{w})$, and exact compliance if $\mathbf{y}>\lambda_{1}(\theta, \mathbf{w})$.

Finally, consider the case in which the father, in absence of court orders, would voluntarily make no child support payment to the mother. This case occurs when the father's income is less than $\underline{\mathbf{y}}(\mathbf{w})$. As before, the father faces two options: he can either make no transfer and bear the cost $\theta$, or choose exact compliance at no cost. If $\lambda_{2}(\theta, \mathbf{w})$ denotes the value of $\mathbf{y}$ which equates the utility value of no child support payment with that of exact compliance, ${ }^{26}$ then a father who makes no transfer will have $\mathbf{y}<\lambda_{2}(\theta, \mathbf{w})$, while a father with $\mathbf{y}>\lambda_{2}(\theta$, w) will exactly comply with the court order.

We now use this extended model to examine how in-work benefit reform affects the compliance behavior of noncustodial parents. For the sake of brevity, we focus on the effects of a singly policy - an increase in the effective wage of the custodial mother. All our results on compliance behavior, however, also apply to a policy that offers greater government transfers $B$ to the custodian. Under the assumption that $\mathbf{y}$ and $\theta$ are independently distributed random variables, we have the following

Proposition 10 A tax-benefit policy reform that aims at increasing the effective wage of custodial mothers would reduce the set of fathers who choose either to overcomply or to exactly comply with child support orders. The set of fathers who choose either to undercomply or to make no child support payment would increase accordingly.

The intuition for this result is straightforward. First, an increase in w reduces the voluntary child support payment that fathers with $\mathbf{y}<\underline{\mathbf{y}}(\mathbf{w})$ would optimally make. This essentially pushes up the income threshold $\mathbf{y}^{+}(\mathbf{w})$ above which fathers choose to overcomply with respect to court orders. Hence, the incidence of overcompliance will decline. Second, for any given value of $\theta$, an increase in $\mathbf{w}$ reduces the utility value of exact compliance relative to that of undercompliance. This is because undercompliance allows fathers to reduce their child support payments optimally in response to an increase in $\mathbf{w}$, while exact compliance does not allow for such utility-maximizing adjustments. Thus, the income threshold $\lambda_{1}(\theta, \mathbf{w})$ shifts outwards. A similar argument establishes that an increase in $\mathbf{w}$ drives a wedge between the utility value of no child support payment and that of exact compliance, and so $\lambda_{2}(\theta, \mathbf{w})$ shifts outwards too. Hence, the incidence of exact compliance will go down.

In general, tax-benefit policies that alter the economic circumstances of divorced parents, especially those programs that try to raise custodial parents' effective wages, may crowd out

The left-hand side of this expression is the utility value of undercompliance, while the right-hand side represents the utility value of exact compliance. Note that $l^{*}(s)$ and $s^{*}$, which are respectively defined in (12) and (14), are functions of $\mathbf{w}$.

${ }^{26}$ Clearly, $\lambda_{2}(\theta, \mathbf{w})$ solves the same expression as $\lambda_{1}(\theta, \mathbf{w})$ earlier, but with the voluntary transfer $s^{*}$ replaced by 0 . 
the voluntary child support transfers from noncustodial parents, even in presence of courtmandated child support awards. Adding child support orders to the institutional environment, therefore, does not qualitatively change our earlier results, implying that the potential for welfare-conditioned benefit reforms to have unintended (and presumably undesirable) consequences remains.

\section{B. Cooperation among Divorced Parents}

Divorced parents could choose to behave cooperatively rather than noncooperatively, as we have assumed so far. Flinn (2000) examines situations in which cooperative behavior among divorced parents arises in a model without taxation. In Flinn's setup, a third party (e.g., the court or a judge) suggests a "focal equilibrium" through specific child support orders. Full compliance with such orders is equivalent to cooperation which, in turn, leads parents to reach efficient levels of child good expenditures. Here, we extend this setup to investigate the extent to which tax-benefit changes affect the emergence of cooperation among divorced parents. Our key question is: How do in-work benefit reforms influence the likelihood of divorced parents to comply with the suggestion of a focal arbitrator on child support transfers and implement a cooperative equilibrium?

For simplicity, we consider the case in which the parents' preference parameters are identical, i.e., $\gamma_{m}=\gamma_{f}=\gamma$. To derive the cooperative allocation of the parents' joint resources, suppose the mother decides not only how much to spend on child goods and how to allocate her time between childcare and market work, but also how much child support she should receive from the father, though her choices are constrained by the father receiving a utility level of at least $\tilde{U}_{f}$. Then, the decision problem of the mother can be represented by

$$
\max _{k, l, s}(\mathbf{w} l+B+s-k)^{\gamma} k^{\alpha}(1-\delta l)^{\beta} \text { s.t. }(y-s)^{\gamma} k^{\alpha}(1-\delta l)^{\beta} \geqslant \tilde{U}_{f}
$$

where $\alpha=a(1-\gamma)$ and $\beta=b(1-\gamma)$. The strict concavity of the parental utility functions implies that the constraint in (16) always binds and that the mother's utility level is a decreasing function of the guaranteed utility level of the father. Moreover, under the assumption that parents have identical preference parameters, the cooperative levels of child goods expenditure $\left(k^{c}\right)$ and time allocated to work $\left(l^{c}\right)$ are independent of the child support payment from the father to the mother, ${ }^{27}$ and can be stated as follows. Define $\pi=\alpha /(\alpha+\gamma)$ and $\ell(\mathbf{w})=$

\footnotetext{
${ }^{27}$ Intuitively, if the mother and the father have identical preferences over consumption and child welfare, there are no conflicts as to how much money should be spent on child goods and how much time should be devoted to parenting.
} 
$[(\alpha+\gamma) \mathbf{w}-\beta \delta(\mathbf{y}+B)] /[\mathbf{w} \delta(\alpha+\beta+\gamma)]$. Then:

$$
l^{c}(\mathbf{w})=\left\{\begin{array}{cl}
0 & \text { if } \mathbf{y} \geqslant \hat{\mathbf{y}}(\mathbf{w}) \\
\ell(\mathbf{w}) & \text { if } \mathbf{y}<\hat{\mathbf{y}}(\mathbf{w})
\end{array} \text { and } k^{c}(\mathbf{w})=\left\{\begin{array}{cl}
\pi(\mathbf{y}+B) & \text { if } \mathbf{y} \geqslant \hat{\mathbf{y}}(\mathbf{w}) \\
\pi[\mathbf{w} \ell(\mathbf{w})+\mathbf{y}+B] & \text { if } \mathbf{y}<\hat{\mathbf{y}}(\mathbf{w})
\end{array}\right.\right.
$$

where $\hat{\mathbf{y}}(\mathbf{w})$ is defined in (15) but with the subscript $f$ suppressed. ${ }^{28}$ Thus, if the noncustodial father enjoys a sufficiently large income (region I in Figure 3), then in a cooperative equilibrium the mother would choose full-time childcare and no paid work, while in the corresponding noncooperative equilibrium she would optimally supply a positive amount of labor to the market. This is consistent with our earlier observation that the noncooperative equilibrium suffers from inefficiently high levels of labor supply.

As in Flinn's (2000) model, we envisage an institutional agent acting as a focal arbitrator and proposing a particular child support order $s^{o}$. The parents then work out whether the child support order is incentive compatible, i.e., they determine whether $s^{o}$ guarantees both of them cooperative utility values that are not exceeded by their respective noncooperative levels. If $s^{o}$ is incentive-compatible, a cooperative equilibrium with $l^{c}(\mathbf{w})$ and $k^{c}(\mathbf{w})$ is implemented. If it is not, then the noncooperative equilibrium is selected.

The set of child support payments under which both parents have an incentive to implement a cooperative equilibrium must be identified. The larger this "cooperation set", the better the chances that the child support order proposed by the focal arbitrator is contained in it. We look at the extremes of this set. The highest child support order compatible with cooperation occurs at a point in which the father obtains his noncooperative utility level and the mother receives the entire surplus from cooperation. Formally,

$$
\begin{gathered}
U_{f}^{*}(\mathbf{w})=(y-\bar{s})^{\gamma}\left[k^{c}(\mathbf{w})\right]^{\alpha}\left[1-\delta l^{c}(\mathbf{w})\right]^{\beta} \\
\Rightarrow \bar{s}(\mathbf{w})=y-\left[U_{f}^{*}(\mathbf{w})\right]^{\frac{1}{\gamma}}\left[k^{c}(\mathbf{w})\right]^{-\frac{\alpha}{\gamma}}\left[1-\delta l^{c}(\mathbf{w})\right]^{-\frac{\beta}{\gamma}}
\end{gathered}
$$

where $U_{f}^{*}(\mathbf{w})$ is the utility level the father would achieve under noncooperation. At the opposite extreme, the lowest child support order compatible with cooperation should occur at a point in which the mother achieves her noncooperative utility level and the father gets the entire surplus from cooperation:

$$
\begin{gathered}
U_{m}^{*}(\mathbf{w})=\left[\mathbf{w} l^{c}(\mathbf{w})+B+\underline{s}-k^{c}(\mathbf{w})\right]^{\gamma}\left[k^{c}(\mathbf{w})\right]^{\alpha}\left[1-\delta l^{c}(\mathbf{w})\right]^{\beta} \\
\Rightarrow \underline{s}(\mathbf{w})=k^{c}(\mathbf{w})-\mathbf{w} l^{c}(\mathbf{w})-B+\left[U_{m}^{*}(\mathbf{w})\right]^{\frac{1}{\gamma}}\left[k^{c}(\mathbf{w})\right]^{-\frac{\alpha}{\gamma}}\left[1-\delta l^{c}(\mathbf{w})\right]^{-\frac{\beta}{\gamma}}
\end{gathered}
$$

\footnotetext{
${ }^{28}$ Note that under the assumption that the ex-spouses have identical preferences, the two income thresholds $\hat{\mathbf{y}}(\mathbf{w})$ and $\tilde{\mathbf{y}}(\mathbf{w})$ are identical.
} 
where $U_{m}^{*}(\mathbf{w})$ is the utility level the mother would achieve under noncooperation. A cooperative equilibrium will be implemented if the child support order $s^{o}$ is contained in the cooperation set, $(\underline{s}(\mathbf{w}), \bar{s}(\mathbf{w}))$.

We now examine how this cooperation set varies with changes in work-conditioned benefits. As before, our focus is on one specific in-work benefit reform, that is, an increase in the effective wage of the custodial mother. In relation to the maximum child support order compatible with a cooperative equilibrium, we establish

Proposition 11 The maximum child support payment that could be observed in cooperative equilibrium, $\bar{s}(\mathbf{w})$, is increasing in $\mathbf{w}$ as long as $\mathbf{y}>\hat{\mathbf{y}}(\mathbf{w})$. It is decreasing in $\mathbf{w}$ whenever $\mathbf{y}<\hat{\mathbf{y}}(\mathbf{w})$.

This proposition has two implications. First, consider high-income divorced couples with $\mathbf{y} \geqslant \hat{\mathbf{y}}(\mathbf{w})$ (region I in Figure 3). In the noncooperative equilibrium of the model of Section 4 , an increase in the effective wage of the mother generates negative welfare effects for divorced parents and their children (Proposition 8). Now, however, a reform that increases the effective wage of the custodian from $\mathbf{w}$ to some $\mathbf{w}^{\prime}>\mathbf{w}$ might lead ex-spouses to behave cooperatively. In particular, when the father's income is high enough (i.e., $\mathbf{y} \geqslant \hat{\mathbf{y}}(\mathbf{w})$ ), then $\bar{s}\left(\mathbf{w}^{\prime}\right)>\bar{s}(\mathbf{w})$ and divorced parents may end up in a cooperative equilibrium, provided that $s^{o} \in\left(\bar{s}(\mathbf{w}), \bar{s}\left(\mathbf{w}^{\prime}\right)\right)$. Put this differently, if $s^{o}>\bar{s}(\mathbf{w})$, the child support order proposed by the focal arbitrator is too high and cooperation cannot be achieved prior to the reform. But the introduction of the reform, by definition, increases the maximum child support compatible with cooperation from $\bar{s}(\mathbf{w})$ to $\bar{s}\left(\mathbf{w}^{\prime}\right)$, and this will induce high-income divorced parents to accept the court's suggestion and thus play cooperatively. This occurs because high-income fathers would suffer utility losses if they continue to behave noncooperatively after the implementation of the reform.

Second, consider low-income fathers who have an income $\mathbf{y}<\hat{\mathbf{y}}(\mathbf{w})$ as in regions II and III of Figure 3. In the noncooperative equilibrium of the model of Section 4, an increase in the effective wage of the mother generates utility gains for divorced parents. Now, instead, a policy reform that increases the wage of the custodian from $\mathbf{w}$ to some $\mathbf{w}^{\prime}>\mathbf{w}$ might induce ex-spouses who would have chosen to behave cooperatively prior to the reform to switch their mode of behavior and play noncooperatively. In fact, when $\mathbf{y}<\hat{\mathbf{y}}(\mathbf{w})$, then $\bar{s}\left(\mathbf{w}^{\prime}\right)<\bar{s}(\mathbf{w})$, and divorced parents will have an incentive to behave noncooperatively provided that $s^{o} \in\left(\bar{s}\left(\mathbf{w}^{\prime}\right), \bar{s}(\mathbf{w})\right)$. For low-income divorced parents, therefore, an effective-wage-increasing policy reform might reduce the likelihood of accepting the child support order suggested by the court and ending up in a cooperative equilibrium. This is because low-income divorced fathers would see their utility levels associated with noncooperation increase after the introduction of the reform. 
Our final result completes the picture and looks at the effects of an increase in the effective wage of the mother on the minimum child support order associated with cooperation. This is given in

Proposition 12 The minimum child support payment that could be observed in cooperative equilibrium, $\underline{s}(\mathbf{w})$, is decreasing in $\mathbf{w}$ as long as $\mathbf{y}>\hat{\mathbf{y}}(\mathbf{w})$. It is ambiguously affected by a change in $\mathbf{w}$ whenever $\mathbf{y}<\hat{\mathbf{y}}(\mathbf{w})$.

Imagine an in-work benefit reform that increases the wage of the custodian from $\mathbf{w}$ to $\mathbf{w}^{\prime}>\mathbf{w}$. If $s^{o}<\underline{s}(\mathbf{w})$, then divorced parents would fail to cooperate prior to the reform because the child support order suggested by the focal arbitrator is too low to be incentive compatible. For high-income fathers, the introduction of the reform will unambiguously reduce the minimum child support payment associated with cooperation, and this might result in parents accepting the arbitrator's proposal and switching to a cooperative equilibrium. Whether such a switch will also be observed among low-income divorced parents is ambiguous.

In sum, when the mode of interaction (cooperative vs noncooperative) between divorced parents is a matter of choice through compliance with court-mandated child support orders and selection of efficient levels of child good expenditures, the introduction of in-work benefit reforms may induce parents to behave either cooperatively or noncooperatively. Divorced couples with high-income fathers, who under noncooperation would suffer from a reform aimed at increasing the effective wage of custodial mothers, might behave cooperatively in response to the reform. From a welfare viewpoint, this switch will translate into a welfare improvement for all parties involved. Conversely, low-income divorced fathers may find it optimal to behave noncooperatively instead of cooperatively. This will lead to a welfare loss. Allowing for cooperation among divorced parents, therefore, does not necessarily alter our earlier results of Section 4. Even when ex-spouses can cooperate, in-work benefit reforms that are meant to improve custodian's effective wages are likely to produce unexpected and undesirable consequences, especially among low-income families. ${ }^{29}$

\section{Conclusions}

\section{Discussion}

Establishing that public policy reforms may have unintended (and, sometimes, undesirable) consequences on behavior and well-being is not new (Moffitt 1992; Blank 2002). Unexpected

\footnotetext{
${ }^{29} \mathrm{An}$ increase in government transfers $B$ generally produces ambiguous effects on the mode of interaction between divorced parents. On the one hand, it increases both parents' utilities from behaving noncooperatively (see Proposition 6), which reduces the likelihood of cooperation. On the other hand, it increases also the parents' utilities from cooperation.
} 
outcomes have been observed not only among individuals and households directly targeted by welfare programs but also among individuals whose behavior and well-being were not meant to be affected (Grogger et al. 2002; Bitler et al. 2005; Grogger and Karoly 2005, 2009; Gregg et al. 2009; Francesconi et al. 2009).

Our results suggest a number of potential undesirable effects that recent in-work benefit reforms introduced in the United States, Canada, the United Kingdom, and other countries may have had. If the generosity of such policies increases through an increase in the level of government transfers received by the custodial parent, then these policies are likely to crowd out the child support transfer made by the noncustodian (Proposition 4). This however does not translate into a reduction of single mothers' utility (see Proposition 6). If, instead, the reform implies an increase in the custodial parent's effective wage, then the noncustodian's transfer is again likely to decline (Proposition 4). This time, however, such a change can lead to a strong substitution effect, with single mothers' increasing their labor supply (Proposition 5). This and the lower transfer from the nonresident father may lead to a reduction in child welfare (Propositions 7 and 8), even when there are court-mandated child support orders (Proposition 10) or when low-income parents can choose to behave cooperatively (Proposition 12).

Can our results help us interpret the evidence on unexpected outcomes found in existing empirical studies? The reduction in single mothers' utility - which may be driven by lower marginal income tax rates and/or higher childcare subsidies, as in Propositions 7 and 8 could be straightforwardly linked to the evidence of worse parental health reported in Baker et al. (2008), who examine the effects of the 1997 childcare reform in Quebec. It could also be related to the estimates shown in Bitler et al. (2005), according to which welfare reform is associated with decreases in health insurance coverage and health care utilization, as well as with increases in the likelihood of needing care but finding it unaffordable. Besides issues of measurement error, the statistically insignificant association between welfare reform and single mothers' self-reported health status in the study by Bitler and colleagues could be the combined result of changes in both basic benefit levels and effective wages as suggested, for example, by our Propositions 6 and 7.

Another aspect of child well-being which has relevance in our context is that in-work benefit reform appears to have led to an increased likelihood of children living with neither parent, especially in the case of black children (Bitler et al. 2006). This unintended consequence is important since living with no parent may be a common detrimental outcome for children whose parents are in jail, deceased, or otherwise unable to care for their children.

Recent empirical research (based both on random-assignment experiments and on nonex- 
perimental data) has found that the effect of welfare and employment policies vary by child developmental stage (Gennetian et al. 2002, 2005; Michalopoulos et al. 2002; Clark-Kauffman et al. 2003; Morris et al. 2005, 2007; Grogger and Karoly 2005, 2009). Programs that increase the incentives of parental employment and family income have been generally found to have negative effects on adolescent children. Most of the same studies, instead, tend to find either neutral or positive effects on pre-school and early-school-age children in low-income households. Ironically, younger children were typically viewed as most at risk for negative impacts of maternal employment in many debates that preceded welfare reform. In contrast, however, other recent studies confirm such concerns, detecting adverse outcomes among very young children. For example, Baker et al. (2008) find evidence suggesting that children aged 0-4 are worse off by measures of aggression, motor and social skills, and illness. Likewise, the results shown in Herbst and Tekin (2008) indicate that childcare subsidies are associated with negative developmental outcomes among US children aged 5-6.

Within our model, the reduction in child welfare can have a straightforward interpretation regardless of developmental stage (Propositions 7 and 8). The model could also provide an insight into possible differential age effects, although this heterogeneity is not directly built into our framework. These might be explained by the possibility that nonresident fathers make larger transfers when children are younger (Weiss and Willis 1993) and, at the same time, custodial mothers are less likely to work as opposed to when children are older. Both greater family income and maternal time can then explain better outcomes of pre-school children. The unexpected worse outcomes of older children can instead be triggered by reduced child support payments from noncustodial fathers (lower family income) and mothers' greater propensity to work (reduced supervision).

Finally, in-work benefit programs introduced in the UK in the late 1990s have also been found to have neutral or beneficial effects on self-esteem, happiness and risky behaviors of children in lone-parent households (Gregg et al. 2009). Some of these heterogenous effects appear to operate through the sex of the child, with boys experiencing better outcomes and girls being left with no change or, possibly, worse outcomes. Whether this differential impact is, at least in part, the result of greater transfers from nonresidential fathers to their sons than to their daughters is something that our model does not explain and remains to be documented empirically. 


\section{Some Pointers for Policy and Future Research}

Our analysis suggests that welfare reform, and especially recent work-conditioned transfer programs, may have unintended consequences among divorced parents and their children. Like earlier models of child support payments (Weiss and Willis 1985; Flinn and Del Boca 1995; Flinn 2000), our model also produces inefficient levels of child support transfers and expenditures on children. Additionally, it emphasizes inefficiencies related to the childcare decisions of noncustodial parents. The introduction of generous in-work benefits, which substantially increase the effective wage of single parents (through either lower marginal income tax rates, or higher childcare subsidies, or both), may aggravate the inefficiency on the custodial side by creating more incentives to work and thus spending less time with children. This policy-induced inefficiency is magnified by an indirect effect that operates through further reductions of the already low child support payments made by noncustodial parents.

What are the implications of our results for future in-work benefit reforms? There is consistent and robust evidence that work-conditioned transfer programs around the world have been quite successful in providing cash assistance to low-income single-parent families without creating adverse incentives for participation in the labor market (e.g., Hotz and Scholz 2003; Blundell and Hoynes 2004; Eissa and Hoynes 2004; Morris et al. 2005; Grogger and Karoly 2005; Francesconi and van der Klaauw 2007; Meyer 2007; Blundell et al. 2008). In fact most studies find such programs to produce positive and meaningful increases in labor supply and total income. However, these positive outcomes notwithstanding, it is unclear whether such programs actually produce significant improvements in the welfare of divorced parents and their children. As indicated by our theoretical findings, in-work benefit reforms may in fact have negative welfare consequences, including that of children. Therefore, in designing welfare-to-work programs special care should be taken to avoid such effects, for example by including provisions for improving the availability of higher quality childcare services and through the introduction of tax incentives or changes in child support orders or in their enforcement to help avoid reductions in the private child support transfers made by fathers. That is, in-work benefit reforms ought to be part of a broader mix of family policies.

There are several extensions and applications we would like to pursue in future research. First, the possibility that divorced parents change their child transfer and expenditure decisions over time (also in response to changes in welfare programs) suggests that a dynamic model can provide a more accurate description of ex-spouses' interactions. Second, some of our rationalizations rest on noncustodial fathers' transfer behavior. Although there are several studies that estimate child support transfer decisions of nonresident fathers (e.g., Weiss and Willis 1993; Del 
Boca and Flinn 1994, 1995; Flinn 2000; Walker and Zhu 2006; Ermisch and Pronzato 2008), relatively little is known about such decisions in response to welfare reforms. This seems to be a promising area for future empirical work. Third, formulating an estimable model that could be taken to longitudinal data on parents and children followed before and after divorce would enormously enhance our insights into the role of parents in shaping child outcomes and our understanding of how this relationship can be influenced by welfare reform.

\section{References}

Baker, Michael, Gruber, Jonathan and Milligan, Kevin (2008). 'Universal Child Care, Maternal Labor Supply, and Family Well-Being', Journal of Political Economy, vol. 116(4), pp. 709-45.

Belsky, Jay (2001). 'Developmental Risks (Still) Associated with Early Child Care', Journal of Child Psychology and Psychiatry, vol. 42(7), pp. 845-59.

Bernal, Raquel and Keane, Michael P. (2008). 'Quasi-Structural Estimation of a Model of Child Care Choices and Child Cognitive Ability Production', Journal of Econometrics, forthcoming.

Bitler, Marianne P., Gelbach, Jonah B., Hoynes, Hilary W. and Zavodny, Madeline (2002). 'The Impact of Welfare Reform on Marriage and Divorce', Demography, vol. 41(2), pp. 216-36.

Bitler, Marianne P., Gelbach, Jonah B. and Hoynes, Hilary W. (2005). 'Welfare Reform and Health', Journal of Human Resources, vol. 40(2), pp. 309-34.

Bitler, Marianne P., Gelbach, Jonah B. and Hoynes, Hilary W. (2006). 'The Impact of Welfare Reform on Children's Living Arrangements', Journal of Human Resources, vol. 41(1), pp. 1-27.

Blank, Rebecca M. (2002). 'Evaluating Welfare Reform in the United States', Journal of Economic Literature, vol. 40(4), pp. 1105-66.

Blundell, Richard, Brewer, Mike and Francesconi, Marco (2008). 'Job Changes and Hours Changes: Understanding the Path of Labor Supply Adjustment', Journal of Labor Economics, vol. 26(3), pp. 421-53.

Blundell, Richard, Chiappori, Pierre-André and Meghir, Costas (2005). 'Collective Labor Supply with Children', Journal of Political Economy, vol. 113(6), pp. 1277-1306.

Blundell, Richard, Chiappori, Pierre-André, Magnac, Thierry and Meghir, Costas (2007). 'Collective Labor Supply: Heterogeneity and Non-Participation', Review of Economic Studies, vol. 74(2), pp. $417-45$.

Blundell, Richard and Hoynes, Hilary (2004). 'Has 'In-Work' Benefit Reform Helped the Labour Market?', in (R. Blundell, D. Card and R.B. Freemand, eds.) Seeking a Premier Economy: The Economic Effects of British Economic Reforms, 1980-2000, Chicago: University of Chicago Press, pp. 411-59.

Brewer, Mike (2008). 'Welfare Reform in the UK: 1997-2007', IFAU Working Paper No. 2008-12, Institute for Labour Market Policy Evaluation, Uppsala. 
Brewer, Mike, Francesconi, Marco, Gregg, Paul and Grogger, Jeffrey (2009) 'Feature: In-Work Benefit Reform in a Cross-National Perspective', Economic Journal, forthcoming.

Browning, Martin and Chiappori, Pierre-André (1998). 'Efficient Intra-household Allocations: A General Characterization and Empirical Tests', Econometrica, vol. 66(6), pp. 1241-78.

Chen, Zhiqi and Woolley, Frances (2001). 'A Cournot-Nash Model of Family Decision Making', Economic Journal, vol. 111, pp. 722-48.

Chiappori, Pierre-André (1992). 'Collective Labor Supply and Welfare', Journal of Political Economy, vol. 100(3), pp. 437-62.

Chiappori, Pierre-André, Iyigun, Murat and Weiss, Yoram (2007). 'Public Goods, Transferable Utility and Divorce Laws', IZA Discussion Paper No. 2646, Institute for the Study of Labor, Bonn.

Chiappori, Pierre-André and Weiss, Yoram (2006). 'Divorce, Remarriage, and Welfare: A General Equilibrium Approach', Journal of the European Economic Association, vol. 4(2-3), pp. 415-26.

Chiappori, Pierre-André and Weiss, Yoram (2007). 'Divorce, Remarriage, and Child Support', Journal of Labor Economics, vol. 25(1), pp. 37-74.

Clark-Kauffman, Elizabeth, Duncan, Gregg J. and Morris, Pamela (2003) 'How Welfare Policies Affect Child and Adolescent Achievement', American Economic Review, vol. 93(2), pp. 299-303.

Del Boca, Daniela and Flinn, Christopher J. (1995). 'Rationalizing Child-Support Decisions', American Economic Review, vol. 85(5), pp. 1241-62.

Duncan, Alan, Giles, Christopher and Webb, Steven (1995). 'The Impact of Subsidising Childcare', EOC Research Report No. 13. Manchester: Equal Opportunities Commission.

Eissa, Nada and Hoynes, Hilary (2004). 'Taxes and the Labor Market Participation of Married Couples: The Earned Income Tax Credit', Journal of Public Economics, vol. 88(9-10), pp. 1931-58.

Ermisch, John F. and Pronzato, Chiara (2008). 'Intra-household Allocation of Resources: Inferences from Non-resident Fathers' Child Support Payments', Economic Journal, vol. 118, pp. 347-62.

Flinn, Christopher J. (2000). 'Modes of Interaction Between Divorced Parents', International Economic Review, vol. 41(3), pp. 545-78.

Francesconi, Marco, Rainer, Helmut and van der Klaauw, Wilbert (2009). 'The Effects of In-Work Benefit Reform in Britain on Couples: Theory and Evidence', Economic Journal, forthcoming.

Francesconi, Marco and van der Klaauw, Wilbert (2007). 'The Socioeconomic Consequences of "InWork" Benefit Reform for British Lone Mothers', Journal of Human Resources, vol. 42(1), pp. 1-31.

Gennetian, Lisa, Duncan, Greg, Knox, Virginia, Vargas, Wanda, Clark-Kauffman, Elizabeth and London, Andrew (2002). How Welfare and Work Policies for Parents Affect Adolescent: A Synthesis of Research. New York: Manpower Demonstration Research Corporation.

Gennetian, Lisa A., Miller, Cynthia and Smith, Jared (2005). Turning Welfare into a Work Support: Six Year Impacts on Parents and Children from the Minnesota Family Investment Program. New York: Manpower Demonstration Research Corporation. 
Gregg, Paul (2008). 'UK Welfare Reform 1996 to 2008 and Beyond: A Personalised and Responsive Welfare System?', CMPO Working Paper Series No. 08/196, University of Bristol.

Gregg, Paul, Harkness, Susan and Smith, Sarah (2009). 'Welfare Reform and Lone Parenting in the UK', Economic Journal, forthcoming.

Grogger, Jeffrey and Karoly, Lynn A. (2005). Welfare Reform: Effects of Decade of Change. Cambridge, MA: Harvard University Press.

Grogger, Jeffrey and Karoly, Lynn A. (2009). 'The Effects of Work-Conditioned Transfers on Marriage and Child Well-Being: A Review', Economic Journal, forthcoming.

Grogger, Jeffrey, Karoly, Lynn A. and Klerman, Jacob A. (2002). 'Consequences of Welfare Reform: A Research Synthesis', Doc. DRU-2676-DHHS by RAND for Administration for Children and Families, U.S. Department of Health and Human Services, Santa Monica, CA.

Gruber, Jonathan (2004). 'Is Making Divorce Easier Bad for Children? The Long-Run Implications of Unilateral Divorce', Journal of Labor Economics, vol. 22(4), pp. 799-834.

Harknett, Kristen and Gennetia, Lisa A. (2003). 'How an Earnings Supplement Can Affect Union Formation Among Low-Income Single Mothers', Demography, vol. 40(3), pp. 451-78.

Herbst, Chris M. and Tekin, Erdal (2008). 'Child Care Subsidies and Child Development', IZA Discussion Paper No. 3836, November.

Hotz, V. Joseph and Scholz, John Karl (2003). 'The Earned Income Tax Credit', in (R.A. Moffitt, ed.) Means-Tested Transfer Programs in the United States. Chicago: University of Chicago Press, pp. $141-97$.

Iyigun, Murat F. and Walsh, Randall P. (2007). 'Endogenous Gender Power, Household Labor Supply and the Demographic Transition', Journal of Development Economics, vol. 82(1), pp. 138-55.

Jarvis, Sarah and Jenkins, Stephen P. (1999). 'Marital Splits and Income Changes: Evidence from the British Household Panel Survey', Population Studies, vol. 53(2), pp. 237-54.

Konrad, Kai A. and Lommerud, Kjell Erik (1995). 'Family Policy with Non-cooperative Families', Scandinavian Journal of Economics, vol. 97(4), pp. 581-601.

Liu, Haiyong, Mroz, Tom and van der Klaauw, Wilbert (2008). 'Maternal Employment and Child Development', Journal of Econometrics, forthcoming.

Lundberg, Shelly J. and Pollak, Robert A. (2003). 'Efficiency in Marriage', Review of Economics of the Household, vol. 1(3), pp. 153-167.

Meyer, Bruce D. (2007). 'The U.S. Earned Income Tax Credit, its Effects, and Possible Reforms', Harris School Working Paper Series No. 07.20, University of Chicago.

Michalopoulos, Charles, Tattie, Doug, Miller, Cynthia, Robins, Philip K., Morris, Pamela A., Gyarmati, David, Redcross, Cindy, Folley Kelly and Ford, Reuben (2002). Making Work Pay: Final Report on the Self-Sufficiency Project for Long-Term Welfare Recipients. Ottawa: Social Research Demonstration Corporation. 
Moffitt, Robert A. (1992). 'Incentive Effects of the U.S. Welfare System: A Review', Journal of Economic Literature, vol. 30(1), pp. 1-61.

Morris, Pamela A., Gennetian, Lisa A. and Duncan, Greg J. (2005). Effects of Welfare and Employment Policies on Young Children: New Findings on Policy Experiments Conducted in the Early 1990s. Society for Research in Child Development Social Policy Report, vol. 19, no. 2.

Morris, Pamela A., Gennetian, Lisa A., Duncan, Greg J. and Huston, Aletha (2007). 'How Welfare Policies Affect Child and Adolescent Development: Investigating Pathways of Influence with Experimental Data', mimeo.

NICHD-ECCRN (National Institute of Child Health and Development-Early Childcare Research Network) (2003). 'Does the Amount of Time Spent in Childcare Predict Socioemotional Adjustment during the Transition to Kindergarten?', Child Development, vol. 74(4), pp. 976-1005.

Page, Marianne E. and Stevens, Ann Huff (2004). 'The Economic Consequences of Absent Parents', Journal of Human Resources, vol. 39(1), pp. 80-107.

Roff, Jennifer (2008). 'A Stackelberg Model of Child Support and Welfare', International Economic Review, vol. 49(2), pp. 515-46.

Stevenson, Betsey (2007). 'The Impact of Divorce Laws on Marriage-Specific Capital', Journal of Labor Economics, vol. 25(1), pp. 75-94.

Stevenson, Betsey and Wolfers, Justin (2006). 'Bargaining in the Shadow of the Law: Divorce Laws and Family Distress', Quarterly Journal of Economics, vol. 121(1), pp. 67-88.

Walker, Ian and Zhu, Yu (2006). 'Child Support and Partnership Dissolution', Economic Journal, vol. 116(510), pp. C93-C109.

Weiss, Yoram and Willis, Robert J. (1985). 'Children as Collective Goods and Divorce Settlements', Journal of Labor Economics, vol. 3(3), pp. 268-92.

Weiss, Yoram and Willis, Robert J. (1993). 'Transfers among Divorced Couples: Evidence and Interpretation', Journal of Labor Economics, vol. 11(4), pp. 629-79.

Wolfers, Justin (2006). 'Did Unilateral Divorce Raise Divorce Rates? A Reconciliation and New Findings', American Economic Review, vol. 96(5), pp. 1802-20. 


\section{Appendix}

Proof of Proposition 1. We now derive the labor supply decision of the mother for some fixed level of $s$. Maximizing (10), the first-order condition for $l$ is:

$$
U_{m} \cdot\left[\frac{\mathbf{w}\left(\alpha_{m}+\gamma_{m}\right)}{\mathbf{w} l+B+s}-\frac{\delta \beta_{m}}{1-\delta l}\right] \leqslant 0
$$

Solving for an interior solution, we obtain:

$$
l=\frac{\left(\alpha_{m}+\gamma_{m}\right) \mathbf{w}-\beta_{m} \delta(B+s)}{\mathbf{w} \delta\left(\alpha_{m}+\beta_{m}+\gamma_{m}\right)} \equiv l^{*}(s)
$$

Clearly, $l$ is strictly positive for all $s<\tilde{s}$, where $\tilde{s}$ is given by (11). Under Assumption $1, l<1$ for all $s \in[0, \tilde{s})$, making $s<\tilde{s}$ necessary and sufficient for an interior solution. A necessary and sufficient condition for $l^{e}=0$ is $s \geqslant \tilde{s}$.

Proof of Proposition 2. Consider the first-order condition to (13) for $s$ when $l^{e}=l^{*}(s)>0$. This is given by:

$$
U_{f} \cdot\left[\delta\left(\alpha_{f}+\beta_{f}\right)-\frac{\gamma_{f}[\mathbf{w}+\delta(s+B)]}{\mathbf{y}-s}\right] \leqslant 0 .
$$

We can solve this for an interior solution to obtain:

$$
s=\frac{\delta\left(\alpha_{f}+\beta_{f}\right) \mathbf{y}-\gamma_{f}(\mathbf{w}+\delta B)}{\delta\left(\alpha_{f}+\beta_{f}+\gamma_{f}\right)} \equiv s^{*} .
$$

A sufficient condition for positive $s$ is $\mathbf{y}>\underline{\mathbf{y}}(\mathbf{w})$, where

$$
\underline{\mathbf{y}}(\mathbf{w})=\frac{\gamma_{f}(\mathbf{w}+\delta B)}{\delta\left(\alpha_{f}+\beta_{f}\right)} .
$$

Observe also that $\tilde{s} \leqslant s^{*}$ for all $\mathbf{y} \geqslant \overline{\mathbf{y}}(\mathbf{w})$, where

$$
\overline{\mathbf{y}}(\mathbf{w})=\underline{\mathbf{y}}(\mathbf{w})+\frac{\tilde{s}\left(\alpha_{f}+\beta_{f}+\gamma_{f}\right)}{\alpha_{f}+\beta_{f}} .
$$

Thus, $\mathbf{y} \in(\mathbf{y}(\mathbf{w}), \overline{\mathbf{y}}(\mathbf{w}))$ is a necessary and sufficient condition for an interior equilibrium with $s^{e}=s^{*}$ and $l^{e}=l^{*}\left(s^{*}\right) \cdot{ }^{30}$ Clearly, a necessary and sufficient condition for a no-support equilibrium with $s^{e}=0$ and $l^{e}=l^{*}(0)$ is $\mathbf{y} \leqslant \underline{\mathbf{y}}(\mathbf{w})$. Finally, a non-employment equilibrium with $l^{e}=0$ arises whenever $\mathbf{y} \geqslant \overline{\mathbf{y}}(\mathbf{w})$. To derive the father's equilibrium transfer when $\mathbf{y} \geqslant \overline{\mathbf{y}}(\mathbf{w})$, consider the first-order condition to (13) for $s$ when $l^{e}=0$. This is given by:

$$
U_{f} \cdot\left[\alpha_{f}-\frac{\gamma_{f}(s+B)}{\mathbf{y}-s}\right] \leqslant 0
$$

Solving for an interior solution, we obtain:

$$
s=\frac{\alpha_{f} \mathbf{y}-\gamma_{f} B}{\alpha_{f}+\gamma_{f}} \equiv \bar{s}
$$

\footnotetext{
${ }^{30}$ Recalling from Assumption 1 that $\underline{\mathbf{w}}=\delta \beta_{m} B /\left(\alpha_{m}+\gamma_{m}\right)$, it is readily checked that $\underline{\mathbf{y}}(\underline{\mathbf{w}})=\overline{\mathbf{y}}(\underline{\mathbf{w}})$.
} 
Now, if $\tilde{s} \leqslant s^{*}$ and $\tilde{s} \geqslant \bar{s}$, then the father's utility function is non-decreasing for $\tilde{s} \leqslant s^{*}$, non-increasing for $\tilde{s} \geqslant \bar{s}$, and therefore maximized by a choice of $\tilde{s}$. Conversely, if $\tilde{s} \leqslant s^{*}$ and $\bar{s}>\tilde{s}$, then the father's utility is maximized by a choice of $\bar{s}$. Hence for $\mathbf{y} \geqslant \overline{\mathbf{y}}(\mathbf{w})$ we have $l^{e}=0$ and $s^{e}=\max \{\bar{s}, \tilde{s}\}$.

Proof of Proposition 3. At an interior equilibrium, where $s^{e}=s^{*}, l^{e}=l^{*}\left(s^{*}\right), \pi_{x}^{e}=\pi_{x}^{*}$ and $\pi_{k}^{e}=\pi_{k}^{*}$, the payoffs of the mother and the father are respectively given by

$$
U_{m}^{*}=\left[\pi_{x}^{*}\left(B+\mathbf{w} l^{*}\left(s^{*}\right)+s^{*}\right)\right]^{\gamma_{m}}\left[\pi_{k}^{*}\left(B+\mathbf{w} l^{*}\left(s^{*}\right)+s^{*}\right)\right]^{\alpha_{m}}\left[1-\delta l^{*}\left(s^{*}\right)\right]^{\beta_{m}}
$$

and

$$
U_{f}^{*}=\left(\mathbf{y}-s^{*}\right)^{\gamma_{f}}\left[\pi_{k}^{*}\left(B+\mathbf{w} l^{*}\left(s^{*}\right)+s^{*}\right)\right]^{\alpha_{f}}\left[1-\delta l^{*}\left(s^{*}\right)\right]^{\beta_{f}} .
$$

First, suppose that the mother chooses to increase child good expenditures according to the assumption of the proposition such that $d \pi_{k}>0$. At an interior equilibrium we have:

$$
\frac{d U_{f}^{*}}{d \pi_{k}}=-U_{f}^{*} \cdot \frac{\alpha_{f}}{\pi_{k}^{*}}>0
$$

and $d U_{m} / d \pi_{k}=0$.

Second, suppose that the mother chooses to decrease labor supply according to the assumption of the proposition such that $d l<0$. At an interior equilibrium we have:

$$
\frac{d U_{f}^{*}}{d l}=-U_{f}^{*} \cdot\left[\frac{\beta_{f}}{\beta_{m}} \frac{\mathbf{w} \delta \pi_{x}^{*}\left(\alpha_{m}+\beta_{m}+\gamma_{m}\right)}{\mathbf{w}+\delta\left(s^{*}+B\right)}\right]<0
$$

and $d U_{m} / d l=0$.

Finally, suppose the father chooses to increase his child support payment according to the assumption of the proposition such that $d s>0$. At an interior equilibrium we have:

$$
\frac{d U_{m}^{*}}{d s}=U_{m}^{*} \cdot\left[\frac{\delta\left(\alpha_{m}+\beta_{m}+\gamma_{m}\right)}{\mathbf{w}+\delta\left(s^{*}+B\right)}\right]>0
$$

and $d U_{f} / d s=0$.

Proof of Proposition 4. To establish Proposition 4, recall from (A.2) that:

$$
s^{*}(B, \mathbf{w})=\frac{\delta\left(\alpha_{f}+\beta_{f}\right) \mathbf{y}-\gamma_{f}(\mathbf{w}+\delta B)}{\delta\left(\alpha_{f}+\beta_{f}+\gamma_{f}\right)}
$$

Partially differentiating this expression with respect to $B$ and $\mathbf{w}$ we obtain:

$$
\frac{\partial s^{*}(\cdot)}{\partial B}=-\frac{\gamma_{f}}{\alpha_{f}+\beta_{f}+\gamma_{f}}<0 \quad \text { and } \quad \frac{\partial s^{*}(\cdot)}{\partial \mathbf{w}}=-\frac{\gamma_{f}}{\delta\left(\alpha_{f}+\beta_{f}+\gamma_{f}\right)}<0 .
$$

Proof of Proposition 5. To prove the proposition, we plug (A.2) into (A.1) and obtain:

$$
l^{*}\left(B, \mathbf{w}, s^{*}(B, \mathbf{w})\right)=\frac{\left[\left(\alpha_{m}+\gamma_{m}\right) \mathbf{w}-\beta_{m} \delta B\right]}{\mathbf{w} \delta\left(\alpha_{m}+\beta_{m}+\gamma_{m}\right)}-\frac{\beta_{m}\left[\delta\left(\alpha_{f}+\beta_{f}\right) \mathbf{y}-\gamma_{f}(\mathbf{w}+\delta B)\right]}{\mathbf{w} \delta\left(\alpha_{f}+\beta_{f}+\gamma_{f}\right)\left(\alpha_{m}+\beta_{m}+\gamma_{m}\right)} .
$$

It is now straightforward to establish the proposition by examining the appropriate partial derivatives of this expression. In particular:

$$
\frac{\partial l^{*}(\cdot)}{\partial B}=-\frac{\beta_{m}\left(\alpha_{f}+\beta_{f}\right)}{\mathbf{w}\left(\alpha_{f}+\beta_{f}+\gamma_{f}\right)\left(\alpha_{m}+\beta_{m}+\gamma_{m}\right)}<0
$$


and

$$
\frac{\partial l^{*}(\cdot)}{\partial \mathbf{w}}=\frac{\beta_{m}\left(\alpha_{f}+\beta_{f}\right)(\mathbf{y}+B)}{\mathbf{w}^{2}\left(\alpha_{f}+\beta_{f}+\gamma_{f}\right)\left(\alpha_{m}+\beta_{m}+\gamma_{m}\right)}>0 .
$$

Proof of Propositions 6 to 9. In the interior equilibrium, the utilities of the father and the mother can be simplified and written as:

$$
\begin{gathered}
U_{f}^{*}(B, \mathbf{w})=\xi_{f}\left(\frac{1}{\mathbf{w}}\right)^{\beta_{f}}[\mathbf{w}+\delta(B+\mathbf{y})]^{\alpha_{f}+\beta_{f}+\gamma_{f}} \\
U_{m}^{*}(B, \mathbf{w})=\xi_{m}\left(\frac{1}{\mathbf{w}}\right)^{\beta_{m}}[\mathbf{w}+\delta(B+\mathbf{y})]^{\alpha_{m}+\beta_{m}+\gamma_{m}}
\end{gathered}
$$

where $\xi_{f}$ and $\xi_{m}$ are positive constants. ${ }^{31}$ Equilibrium child welfare is given by:

$$
C^{*}(B, \mathbf{w})=\xi_{c}\left(\frac{1}{\mathbf{w}}\right)^{b}[\mathbf{w}+\delta(B+\mathbf{y})]^{a+b}
$$

where $\xi_{c}$ is a positive constant. It is now straightforward to check that an increase in $B$ would (i) raise the utilities of the father and the mother and (ii) increase child welfare. Proposition 6 follows immediately.

It is also straightforward to verify that

$$
\begin{gathered}
\frac{\partial U_{f}^{*}(\cdot)}{\partial \mathbf{w}} \gtreqless 0 \Leftrightarrow \mathbf{y} \lesseqgtr \frac{\left(\alpha_{f}+\gamma_{f}\right) \mathbf{w}-\beta_{f} \delta B}{\beta_{f} \delta} \equiv \hat{\mathbf{y}}(\mathbf{w}) \\
\frac{\partial U_{m}^{*}(\cdot)}{\partial \mathbf{w}} \gtreqless 0 \Leftrightarrow \mathbf{y} \lesseqgtr \frac{\left(\alpha_{m}+\gamma_{m}\right) \mathbf{w}-\beta_{m} \delta B}{\beta_{m} \delta} \equiv \tilde{\mathbf{y}}(\mathbf{w}) \\
\frac{\partial C^{*}(\cdot)}{\partial \mathbf{w}} \gtreqless 0 \Leftrightarrow \mathbf{y} \lesseqgtr \frac{a \mathbf{w}-b \delta B}{b \delta} \equiv \breve{\mathbf{y}}(\mathbf{w})
\end{gathered}
$$

We first note that $\hat{\mathbf{y}}(\mathbf{w})>\breve{\mathbf{y}}(\mathbf{w})$ for all $\gamma_{f}>0$. Similarly, $\tilde{\mathbf{y}}(\mathbf{w})>\breve{\mathbf{y}}(\mathbf{w})$ for all $\gamma_{m}>0$. Next, recall that a necessary condition for an interior equilibrium is $\mathbf{y}>\underline{\mathbf{y}}(\mathbf{w})$, where $\underline{\mathbf{y}}(\mathbf{w})$ is defined in (A.3). We can now prove Propositions 7 to 9 .

First, if $\hat{\mathbf{y}}(\mathbf{w}) \leqslant \underline{\mathbf{y}}(\mathbf{w})$ and $\tilde{\mathbf{y}}(\mathbf{w}) \leqslant \underline{\mathbf{y}}(\mathbf{w})$ for all $\mathbf{w} \in(\underline{\mathbf{w}}, \overline{\mathbf{w}}),{ }^{32}$ then $\mathbf{y}>\hat{\mathbf{y}}(\mathbf{w})$ and $\mathbf{y}>\tilde{\mathbf{y}}(\mathbf{w})$ for all $\mathbf{y}>\underline{\mathbf{y}}(\mathbf{w})$. In this case, the sets $(\overline{\mathbf{y}}(\mathbf{w}), \hat{\mathbf{y}}(\mathbf{w}))$ and $(\underline{\mathbf{y}}(\mathbf{w}), \tilde{\mathbf{y}}(\mathbf{w}))$ are empty. As a consequence, $\partial U_{i}^{*}(\cdot) / \overline{\partial \mathbf{w}}<0(i=f, m)$ and $\partial C^{*}(\cdot) / \bar{\partial} \mathbf{w}<0$ for all $\mathbf{y}>\overline{\mathbf{y}}(\mathbf{w})$. Now, it is straightforward to see that $\underline{\mathbf{y}}(\mathbf{w}), \hat{\mathbf{y}}(\mathbf{w})$ and $\tilde{\mathbf{y}}(\mathbf{w})$ are linear in $\mathbf{w}$. Next, it is easy to check that $\hat{\mathbf{y}}(\underline{\mathbf{w}})<\underline{\mathbf{y}}(\underline{\mathbf{w}})$ and $\tilde{\mathbf{y}}(\underline{\mathbf{w}})<\underline{\mathbf{y}}(\underline{\mathbf{w}})$. $\bar{T}$ Thus, to have $\hat{\mathbf{y}}(\mathbf{w}) \leqslant \underline{\mathbf{y}}(\mathbf{w})$ and $\tilde{\mathbf{y}}(\mathbf{w}) \leqslant \underline{\mathbf{y}}(\mathbf{w})$ for all $\mathbf{w} \in(\underline{\mathbf{w}}, \overline{\mathbf{w}})$, it is necessary that $\hat{\mathbf{y}}(\overline{\mathbf{w}}) \leqslant \underline{\mathbf{y}}(\overline{\mathbf{w}})$ and $\tilde{\mathbf{y}}(\overline{\mathbf{w}}) \leqslant \underline{\mathbf{y}}(\overline{\mathbf{w}})$. Simple algebra shows that $\hat{\mathbf{y}}(\overline{\mathbf{w}}) \leqslant \underline{\mathbf{y}}(\overline{\mathbf{w}}) \Leftrightarrow \gamma_{m} \geqslant \bar{\gamma}$ and $\tilde{\mathbf{y}}(\overline{\mathbf{w}}) \leqslant \underline{\mathbf{y}}(\overline{\mathbf{w}}) \Leftrightarrow \gamma_{f} \geqslant \bar{\gamma}$, where $\bar{\gamma} \equiv \delta(\bar{a}+b) /[(1-\delta)+\delta(a+b)]$. Proposition 7 follows immediately.

Next, if $\gamma_{m}<\bar{\gamma}$, then $\hat{\mathbf{y}}(\mathbf{w})>\underline{\mathbf{y}}(\mathbf{w})$ for all $\mathbf{w} \in(\hat{\mathbf{w}}, \overline{\mathbf{w}})$, where $\hat{\mathbf{w}}=\delta \beta_{f} B / \alpha_{f}$; similarly, if $\gamma_{f}<\bar{\gamma}$, then $\tilde{\mathbf{y}}(\mathbf{w})>\underline{\mathbf{y}}(\mathbf{w})$ for all $\mathbf{w} \in(\tilde{\mathbf{w}}, \overline{\overline{\mathbf{w}}})$, where $\tilde{\mathbf{w}}=\beta_{m} \delta B\left(\alpha_{f}+\beta_{f}+\gamma_{f}\right) /\left[\left(\alpha_{m}+\gamma_{m}\right)\left(\alpha_{f}+\beta_{f}\right)-\gamma_{f} \beta_{m}\right]$. Thus, if $\gamma_{m}<\bar{\gamma}$ and $\gamma_{f}<\bar{\gamma}$, the sets $(\mathbf{y}(\mathbf{w}), \hat{\mathbf{y}}(\mathbf{w}))$ and $(\mathbf{y}(\mathbf{w}), \tilde{\mathbf{y}}(\mathbf{w}))$ are non-empty, but inspection of (A.11) to (A.13) readily reveals that $\left.\partial U_{i}^{*}(\cdot) / \partial \mathbf{w}<0 \overline{(i}=f, m\right)$ and $\partial C^{*}(\cdot) / \partial \mathbf{w}<0$ for all $\mathbf{y}>$ $\max \{\hat{\mathbf{y}}(\mathbf{w}), \tilde{\mathbf{y}}(\mathbf{w})\}$. Proposition 8 follows immediately.

\footnotetext{
${ }^{31}$ To obtain this, we substitute (A.7) and (A.8), as well as (9), into (A.5) and (A.6), respectively.

${ }^{32}$ Recall that $\underline{\mathbf{w}}=\delta \beta_{m} B /\left(\alpha_{m}+\gamma_{m}\right)$ and $\overline{\mathbf{w}}=\delta \beta_{m} B /\left[(1-\delta)\left(\alpha_{m}+\gamma_{m}\right)-\delta \beta_{m}\right]$, respectively.
} 
Finally, it is fairly straightforward, though tedious, to show that if

$$
\gamma_{f}<\frac{(a+b)\left[\delta\left(\alpha_{m}+\beta_{m}\right)-(1-\delta) \gamma_{m}\right]}{(1-\delta)\left[\alpha_{m}+\beta_{m}+\gamma_{m}\right]+(a+b)\left[\delta\left(\alpha_{m}+\beta_{m}\right)-(1-\delta) \gamma_{m}\right]},
$$

then $\breve{\mathbf{y}}(\mathbf{w})>\underline{\mathbf{y}}(\mathbf{w})$ for all $\mathbf{w} \in(\breve{\mathbf{w}}, \overline{\mathbf{w}})$, where $\breve{\mathbf{w}}=b \delta B\left(\alpha_{f}+\beta_{f}+\gamma_{f}\right) /\left[a\left(\alpha_{f}+\beta_{f}\right)-b \gamma_{f}\right]$. To see this, notice first that $\breve{\mathbf{y}}(\mathbf{w})$ and $\underline{\mathbf{y}}(\mathbf{w})$ are linear in $\mathbf{w}$. Next, it is readily checked that $\breve{\mathbf{y}}(\underline{\mathbf{w}})<\underline{\mathbf{y}}(\underline{\mathbf{w}})$. Thus, to have $\breve{\mathbf{y}}(\mathbf{w})>\mathbf{y}(\mathbf{w})$ for some $\mathbf{w}<\overline{\mathbf{w}}$, it is necessary that $\breve{\mathbf{y}}(\overline{\mathbf{w}})>\mathbf{y}(\overline{\mathbf{w}})$. Equation (A.14) follows immediately after solving this inequality for $\gamma_{f}$. In the case where $\breve{\mathbf{y}}(\mathbf{w})>\mathbf{y}(\mathbf{w})$ for all $\mathbf{w} \in(\breve{\mathbf{w}}, \overline{\mathbf{w}})$, the set $(\underline{\mathbf{y}}(\mathbf{w}), \breve{\mathbf{y}}(\mathbf{w}))$ is non-empty, and inspection of (A.11) to (A.13) readily reveals that $\partial U_{i}^{*}(\cdot) / \partial \mathbf{w}>0$ $(i=\bar{f}, m)$ and $\partial C^{*}(\cdot) / \partial \mathbf{w}>0$ for all $\mathbf{y}<\breve{\mathbf{y}}(\mathbf{w})$. Proposition 9 follows immediately.

Proof of Proposition 10. The income threshold above which fathers choose to overcomply with respect to court orders is given by:

$$
\mathbf{y}^{+}(\mathbf{w})=\frac{\gamma_{f}(\mathbf{w}+\delta B)+s^{o} \delta\left(\alpha_{f}+\beta_{f}+\gamma_{f}\right)}{\delta\left(\alpha_{f}+\beta_{f}\right)} .
$$

Simple differentiation shows that

$$
\frac{\partial \mathbf{y}^{+}(\cdot)}{\partial \mathbf{w}}=\frac{\gamma_{f}}{\delta\left(\alpha_{f}+\beta_{f}\right)}>0
$$

This establishes that an increase in the effective wage of custodial mothers would reduce the set of fathers who choose to overcomply with child support orders.

Consider now the case in which a father's income is less than $\mathbf{y}^{+}(\mathbf{w})$ but more than $\underline{\mathbf{y}}(\mathbf{w})$. The utility value of undercompliance is given by

$$
U_{f}^{u n}(\mathbf{w})=U_{f}^{*}(\mathbf{w})-\theta \quad \text { where } \quad U_{f}^{*}(\mathbf{w})=\xi_{f}\left(\frac{1}{\mathbf{w}}\right)^{\beta_{f}}[\mathbf{w}+\delta(B+\mathbf{y})]^{\alpha_{f}+\beta_{f}+\gamma_{f}}
$$

while the utility value of exact compliance is

$$
U_{f}^{e x}(\mathbf{w})=\xi_{e}\left(\mathbf{y}-s^{o}\right)^{\gamma_{f}}\left(\frac{1}{\mathbf{w}}\right)^{\beta_{f}}\left[\mathbf{w}+\delta\left(B+s^{o}\right)\right]^{\alpha_{f}+\beta_{f}}
$$

where $\xi_{e}$ is a positive constant. Now let $\Sigma(\mathbf{w})=U_{f}^{u n}(\mathbf{w})-U_{f}^{e x}(\mathbf{w})$. Defining

$$
\kappa^{*}(\mathbf{w})=\frac{\left(\alpha_{f}+\gamma_{f}\right) \mathbf{w}-\beta_{f} \delta(\mathbf{y}+B)}{\mathbf{w}[\mathbf{w}+\delta(\mathbf{y}+B)]} \quad \text { and } \quad \kappa^{e x}(\mathbf{w})=\frac{\alpha_{f} \mathbf{w}-\beta_{f} \delta\left(s^{o}+B\right)}{\mathbf{w}\left[\mathbf{w}+\delta\left(s^{o}+B\right)\right]}
$$

it is straightforward to show that

$$
\frac{\partial \Sigma(\cdot)}{\partial \mathbf{w}}=U_{f}^{*}(\mathbf{w}) \cdot \kappa^{*}(\mathbf{w})-U_{f}^{e x}(\mathbf{w}) \cdot \kappa^{e x}(\mathbf{w})>0
$$

That we have $\partial \Sigma(\cdot) / \partial \mathbf{w}>0$ uses the fact that $U_{f}^{*}(\mathbf{w})>U_{f}^{e x}(\mathbf{w})$ and $\kappa^{*}(\mathbf{w})>\kappa^{e x}(\mathbf{w})$ for all $\mathbf{y}<\mathbf{y}^{+}(\mathbf{w})$. The fact that an increase in $\mathbf{w}$ increases the difference between the utility values of undercompliance and exact compliance implies that the set of fathers who choose to exactly comply with child support orders shrinks. 
Finally, consider the case in which a father's income is less than $\mathbf{y}(\mathbf{w})$. In this case, a father would voluntarily make no child support payment to the mother, and the corresponding utility value is given by

$$
U_{f}^{n o}(\mathbf{w})=U_{f}^{0}(\mathbf{w})-\theta \quad \text { where } \quad U_{f}^{0}(\mathbf{w})=\xi_{0} \mathbf{y}_{f}^{\gamma}\left(\frac{1}{\mathbf{w}}\right)^{\beta_{f}}[\mathbf{w}+\delta B]^{\alpha_{f}+\beta_{f}}
$$

where $\xi_{0}$ is a positive constant. Now let $\Upsilon(\mathbf{w})=U_{f}^{n o}(\mathbf{w})-U_{f}^{e x}(\mathbf{w})$. Defining

$$
\kappa^{0}(\mathbf{w})=\frac{\alpha_{f} \mathbf{w}-\beta_{f} \delta B}{\mathbf{w}(\mathbf{w}+\delta B)}
$$

it is straightforward to show that

$$
\frac{\partial \Upsilon(\cdot)}{\partial \mathbf{w}}=U_{f}^{0}(\mathbf{w}) \cdot \kappa^{0}(\mathbf{w})-U_{f}^{e x}(\mathbf{w}) \cdot \kappa^{e x}(\mathbf{w})>0
$$

That we have $\partial \Upsilon(\cdot) / \partial \mathbf{w}>0$ uses the facts that $U_{f}^{0}(\mathbf{w})>U_{f}^{e x}(\mathbf{w})$ for all $\mathbf{y}<\underline{\mathbf{y}}(\mathbf{w})$ and $\kappa^{0}(\mathbf{w})>\kappa^{e x}(\mathbf{w})$ for all $s^{o}>0$. The fact that an increase in $\mathbf{w}$ increases the difference between the utility values of no child support payment and exact compliance implies that the set of fathers who choose to exactly comply with child support orders shrinks. Proposition 10 now follows immediately.

Proof of Proposition 11. Substituting (A.9) into (18), we obtain:

$\bar{s}(\mathbf{w})=y-\Gamma(\mathbf{w}) \quad$ where $\quad \Gamma(\mathbf{w}) \equiv\left[\xi_{f}\left(\frac{1}{\mathbf{w}}\right)^{\beta}(\mathbf{w}+\delta(B+\mathbf{y}))^{\alpha+\beta+\gamma}\right]^{\frac{1}{\gamma}}\left[k^{c}(\mathbf{w})\right]^{-\frac{\alpha}{\gamma}}\left[1-\delta l^{c}(\mathbf{w})\right]^{-\frac{\beta}{\gamma}}$.

First, suppose that $\mathbf{y}>\hat{\mathbf{y}}(\mathbf{w})$. Then $l^{c}(\mathbf{w})=0$ and $k^{c}=\alpha(\mathbf{y}+B) /(\alpha+\gamma)$, and simply differentiation shows that

$$
\frac{\partial \bar{s}(\cdot)}{\partial \mathbf{w}}=\Gamma(\mathbf{w}) \cdot\left[\frac{\beta \delta(\mathbf{y}+B)-(\alpha+\gamma) \mathbf{w}}{\gamma \mathbf{w}[\mathbf{w}+\delta(\mathbf{y}+B)]}\right]>0 \quad \text { for all } \quad \mathbf{y}>\hat{\mathbf{y}}(\mathbf{w}) .
$$

Next, suppose that $\mathbf{y}<\hat{\mathbf{y}}(\mathbf{w})$. Then $l^{c}(\mathbf{w})=\ell(\mathbf{w})$ and $k^{c}=\alpha[\mathbf{w} \ell(\mathbf{w})+\mathbf{y}+B] /(\alpha+\gamma)$, where $\ell(\mathbf{w})=[(\alpha+\gamma) \mathbf{w}-\beta \delta(\mathbf{y}+B)] /[\mathbf{w} \delta(\alpha+\beta+\gamma)]$. Now differentiation shows that:

$$
\frac{\partial \bar{s}(\cdot)}{\partial \mathbf{w}}=-\Gamma(\mathbf{w}) \cdot\left[\frac{1}{\mathbf{w}+\delta(\mathbf{y}+B)}\right]<0
$$

Proposition 11 follows immediately.

Proof of Proposition 12. Substituting (A.10) into (19), we obtain:

$$
\begin{gathered}
\underline{s}(\mathbf{w})=k^{c}(\mathbf{w})-\mathbf{w} l^{c}(\mathbf{w})-B+\Lambda(\mathbf{w}) \\
\text { where } \Lambda(\mathbf{w}) \equiv\left[\xi_{m}\left(\frac{1}{\mathbf{w}}\right)^{\beta}(\mathbf{w}+\delta(B+\mathbf{y}))^{\alpha+\beta+\gamma}\right]^{\frac{1}{\gamma}}\left[k^{c}(\mathbf{w})\right]^{-\frac{\alpha}{\gamma}}\left[1-\delta l^{c}(\mathbf{w})\right]^{-\frac{\beta}{\gamma}} .
\end{gathered}
$$

First, suppose that $\mathbf{y}>\hat{\mathbf{y}}(\mathbf{w})$. Then $l^{c}(\mathbf{w})=0$ and $k^{c}=\alpha(\mathbf{y}+B) /(\alpha+\gamma)$, and simple differentiation shows that

$$
\frac{\partial \underline{s}(\cdot)}{\partial \mathbf{w}}=-\Lambda(\mathbf{w}) \cdot\left[\frac{\beta \delta(\mathbf{y}+B)-(\alpha+\gamma) \mathbf{w}}{\gamma \mathbf{w}[\mathbf{w}+\delta(\mathbf{y}+B)]}\right]<0 \quad \text { for all } \quad \mathbf{y}>\hat{\mathbf{y}}(\mathbf{w}) .
$$

Next, suppose that $\mathbf{y}<\hat{\mathbf{y}}(\mathbf{w})$. Then $l^{c}(\mathbf{w})=\ell(\mathbf{w})$ and $k^{c}=\alpha[\mathbf{w} \ell(\mathbf{w})+\mathbf{y}+B] /(\alpha+\gamma)$, where $\ell(\mathbf{w})=[(\alpha+\gamma) \mathbf{w}-\beta \delta(\mathbf{y}+B)] /[\mathbf{w} \delta(\alpha+\beta+\gamma)]$. Now differentiation shows that:

$$
\frac{\partial \underline{s}(\cdot)}{\partial \mathbf{w}}=-\left[\frac{\gamma}{\delta(\alpha+\beta+\gamma)}\right]+\Lambda(\mathbf{w}) \cdot\left[\frac{1}{\mathbf{w}+\delta(\mathbf{y}+B)}\right]=\text { ambiguous }
$$

Proposition 12 follows immediately. 